\title{
Achievements and Challenges of Genomics-Assisted Breeding in Forest Trees: From Marker-Assisted Selection to Genome Editing
}

\author{
Sunny Ahmar ${ }^{1}\left(\mathbb{D}\right.$, Paulina Ballesta ${ }^{2, *}$, Mohsin Ali $^{3}$ and Freddy Mora-Poblete ${ }^{1, *(\mathbb{D}}$ \\ 1 Institute of Biological Sciences, University of Talca, 1 Poniente 1141, Talca 3460000, Chile; \\ sunnyahmar13@gmail.com \\ 2 The National Fund for Scientific and Technological Development, Av. del Agua 3895, Talca 3460000, Chile \\ 3 Department of Forestry and Range Management, University of Agriculture Faisalabad, \\ Faisalabad 38000, Pakistan; mohsinali_uaf@hotmail.com \\ * Correspondence: paballesta@gmail.com (P.B.); morapoblete@gmail.com (F.M.-P.)
}

Citation: Ahmar, S.; Ballesta, P.;

Ali, M.; Mora-Poblete, F.

Achievements and Challenges of Genomics-Assisted Breeding in Forest Trees: From Marker-Assisted Selection to Genome Editing. Int. J. Mol. Sci. 2021, 22, 10583. https:// doi.org/10.3390/ijms221910583

Academic Editor: Matthias Fladung

Received: 3 September 2021

Accepted: 27 September 2021

Published: 30 September 2021

Publisher's Note: MDPI stays neutral with regard to jurisdictional claims in published maps and institutional affiliations.

Copyright: (c) 2021 by the authors. Licensee MDPI, Basel, Switzerland. This article is an open access article distributed under the terms and conditions of the Creative Commons Attribution (CC BY) license (https:/ / creativecommons.org/licenses/by/ $4.0 /)$.

\begin{abstract}
Forest tree breeding efforts have focused mainly on improving traits of economic importance, selecting trees suited to new environments or generating trees that are more resilient to biotic and abiotic stressors. This review describes various methods of forest tree selection assisted by genomics and the main technological challenges and achievements in research the genomic level. Due to the long rotation time of a forest plantation and the resulting long generation times necessary to complete a breeding cycle, the use of advanced techniques with traditional breeding have been necessary, allowing the use of more precise methods for determining the genetic architecture of traits of interest, such as genome-wide association studies (GWASs) and genomic selection (GS). In this sense, main factors that determine the accuracy of genomic prediction models are also addressed. In turn, the introduction of genome editing opens the door to new possibilities in forest trees and especially clustered regularly interspaced short palindromic repeats and CRISPR-associated protein 9 (CRISPR/Cas9). It is a highly efficient and effective genome editing technique that has been used to effectively implement targetable changes at specific places in the genome of a forest tree. In this sense, forest trees still lack a transformation method and an inefficient number of genotypes for CRISPR/Cas9. This challenge could be addressed with the use of the newly developing technique GRF-GIF with speed breeding.
\end{abstract}

Keywords: Bayesian genomic prediction; BLUP; CRISPR/Cas9; GRF-GIF; forest tree improvement

\section{Introduction}

Forest trees are a main source of wood, energy, pulp for paper, soil protection, correction of erosion problems and silvopastoral plantations, among other things. In this sense, important efforts in forest tree breeding have been carried out to improve traits of economic interest, to select trees (or hybrids) adapted to new habitats, or to generate trees that are more tolerant to various biotic and abiotic stresses. From the point of view of wood productivity, conventional breeding programs have continuously been improving traits related to throughput, such as wood volume, tree height, diameter at breast height, stem straightness, survival and wood quality, under various environmental conditions [1-7].

Conventional forest tree breeding considers phenotypic evaluations based on kinship relationships between individuals to identify trees that are superior in a trait of interest. The Henderson mixed-model method has been traditionally used to determine the genetic merit of trees and best linear unbiased prediction (BLUP) has been the standard prediction method [8,9]. The genetic merit is predicted according to the degree of kinship between the trees of a breeding population under the assumption that individuals with a common ancestor are phenotypically similar and share loci of interest. Due to the long rotation 
time of a forest plantation and the resulting long generation times necessary to complete a breeding cycle, the advent of molecular marker technology along with traditional phenotypic selection has led to the development of marker-assisted selection (MAS) [10]. With MAS, important advances have been made in forest selection and breeding. In this method, the genotypic values of individuals are predicted by considering the effects of selected markers, which predictions are more accurate for traits controlled by few quantitative trait loci (QTLs), each of which controls a relatively large proportion of the phenotypic variation [11]. On the other hand, the development of high-throughput genotyping techniques has allowed the use of more precise methods for determining the genetic architecture of traits of interest, such as genome-wide association studies (GWASs) and genomic selection (GS). For example, GS is a method that uses molecular markers distributed throughout the genome, such as single-nucleotide polymorphisms (SNPs), which is preferred for complex traits that are affected by many genes and are strongly affected by the environment [12-14].

Both in traditional selection methods and in GS, the predictive accuracy of the phenotype of an individual depends on how accurate the estimation of the genetic relationships between individuals is [15-17]. The predictive power of a GS model can be greater if the individuals which are used as references to estimate the additive effects (of the loci) are genetically related to the individuals whose phenotype is to be predicted [17-19]. In this context, to make good use of GS, several genetic factors that are intrinsic to the study population should be considered [20], such as linkage disequilibrium (LD) patterns, the genetic structure of the population and genetic diversity, among others [21-24] in order to optimize the rates of genetic gain. Kinship relationships derived from pedigrees represent the (theoretical) proportion of the genome that is shared between individuals. This makes the relationship matrix generated by genealogical background an unbiased estimate of the kinship relationships between the genes that control the phenotype $[15,25]$. However, in some populations, it is not possible to perform a good reconstruction of the genetic structure that defines the population (for example, due to pollen contamination or in open pollination assays), which leads to lower precision in the estimation of genetic parameters [26]. Even events in the evolutionary history of the population could be ignored, which would make it difficult to accurately estimate the genetic parameters that are key in the selection of superior trees. In this sense, kinship estimates based on genomic regions are a better approximation of the real proportion of the genome that two individuals share. Currently, kinship between individuals is determined based on SNPs or haplotypes [27-29]. According to Edwards (2015) [27], haplotypes can establish more precise and reliable genealogical relationships than a relationship matrix made purely from SNPs because they allow us to examine the identity by descent that exists among the individuals of a population. Interestingly, haplotypes have been used in GS models, covering extensive regions of the genome of some annual plants (such as wheat and maize), which has increased the predictive power of complex phenotypic traits [30-34]. Interestingly, the haplotype approach can be especially beneficial for predicting traits with a relatively low heritability. Some authors suggest that these results can be explained by the fact that the use of haplotypes in GS allows access to heritable genetic components that cannot be detected by SNPs [31,35]. Despite these possible benefits demonstrated in silico and experimentally, there is still little information on the use of haplotypes in GS, especially in forest trees. In Eucalyptus globulus Labill., Ballesta et al. (2019) [36] emphasized that a GS model that uses haplotypes as predictor variables can increase the ability to predict traits with low genetic control by up to $21 \%$. In addition, Mora-Poblete et al. (2021) [3] showed that the genomic prediction of some metabolites and components of leaves could become more accurate with the use of haplotypes in Eucalyptus cladocalyx F. Muell.

On the other hand, with the advent of genomic editing, great opportunities are visualized in terms of the future development of plant science, including in forest trees and in the rapid remodeling of crops. Genome editing is a relevant, versatile and preferred tool for the improvement of annual crops, as well as for functional genomics [37]. Great advances have been made in gene editing techniques, such as those using zinc finger 
nucleases (ZFNs), transcription activator-type effector nucleases (TALENs) and clustered regularly interspaced short palindromic repeats (CRISPR) associated with the Cas9 and Cpf1 proteins [38-42]. Among the various genome editing tools, CRISPR has become the most popular, which has helped to clarify the genomic structure and its role in plants, for example, the transcriptional control of Cas9 and Cpf1, the monitoring of a genetic locus, the mechanism and control of the promoter activity of a gene and the alteration and detection of epigenetic behavior at SNPs as found through GWASs $[38,43,44]$. This review describes various methods of forest tree selection assisted by genomics, from MAS to genomic editing and the main technological challenges, highlighting the achievements and advances in research at the genomic level.

\section{Conventional Forest Tree Breeding and Marker-Assisted Selection (MAS)}

In conventional forest tree breeding, phenotypic evaluations are performed and kinship relationships are determined to identify the trees that are superior in a trait of interest [26,45-47]. In general, evaluations are carried out in progeny trials, such as half and/or full siblings, clones, hybrids, or a combination there of them [48-50]. Phenotypic selection has contributed significantly to the increase in genetic gains in various forest species around the world, such as Eucalyptus, Pinus, Populus, Picea and Cryptomeria [51-55]. However, the maintenance of progeny trials, for example, involves a significant investment of resources, intensive logistics and long selection cycles before usable results are seen $[10,56,57]$.

Parental genotypes are evaluated by the throughput of their progeny, such that allelic combinations that generate offspring with superior throughput are considered genetically superior and are put into successive breeding cycles. Therefore, an accurate estimation or prediction of the "breeding value" of an individual is required. On the other hand, it is common that it is complicated to analyze the results of a forest competition trial because (1) usually only a subset of the parents is represented in each progeny trial; (2) the parents are represented in different number of progeny trials; (3) the trials are evaluated at different ages of the trees; and (4) the kinship background between individuals may be wrong due to the management of a seed orchard or even due to inbreeding processes $[26,58]$. The historical innovation for the breeding value estimation model taken into account the effects caused by the genotypes as random effects instead of fixed [59-62]. This analytical method, known as best linear prediction (BLP) or best linear unbiased prediction (BLUP), allows the maximization of the precision or the correlation between the predicted and real values for genetic merits, which includes the pedigree information of the individuals evaluated [63]. In this sense, the use of the Henderson mixed-model method (based on BLUP) has traditionally been used to determine the genetic merit of trees and it is considered a standard prediction method [8,9]. The genetic merit is predicted according to the degree of kinship between the trees of a breeding population under the assumption that individuals with a common ancestor are phenotypically similar and share loci of interest. However, conventional breeding has allowed significant genetic gains in different forest species $[4,49,64]$, even when it presents clear disadvantages, such as the long generation time required to complete a breeding cycle $[10,65]$. The advent of molecular marker technology, in combination with traditional phenotypic selection, has led to the development of marker-assisted selection (MAS) [10]. With MAS, important advances have been achieved in forest selection and breeding. MAS predicts the genetic merit of the trees by considering the effects of a group of selected markers (considering their statistical significance) and it has become the preferred way to improve traits controlled by few loci, each of which controls a relatively large proportion of the phenotypic variation $[13,66]$.

\section{High-Throughput Genotyping Techniques Enable Different Fields of Studies on Plants}

Molecular markers have been widely used in genetic and plant breeding studies [67-70]. SNPs, for example, are abundant in plant genomes and their usefulness as genetic markers has been well established in the last decade [71]. For this reason, SNP markers have been applied to various areas of knowledge, such as forensic science and diagnostics in 
humans, aquaculture, livestock marker-assisted selection, agricultural crop breeding and conservation studies [72-76].

In 2011, the number of sequenced plant genomes doubled compared to the previous decade (http:/ / phytozome.net, accessed on 1 September 2021), which was due to the increasing throughput of sequencing methods. Second- and third-generation sequencing platforms, such as Illumina's various platforms, 454 pyrosequencing (Roche), SOLID (Invitrogen) and Ion Torrent (Invitrogen), have the ability to obtain results from many sequences, which can be used to discover new molecular markers in a viable way and at low cost $[77,78]$. These techniques have been used on a large scale for the discovery of SNPs in representative sets of individuals of various species of plants, such as rice [79], wheat [80] and different trees [81,82]. The discovery of SNP markers has made important contributions to advancements in various fields of study, such as genomics, transcriptomics and population genetics, such as for mapping QTLs. Through knowledge of the genome and the physical locations of these polymorphisms, DNA arrays have been made to type SNPs of different species, such as cacao [83], cherry [84], wheat [85] and rice [86].

Given the need for molecular tools that support genomic studies of species of interest in forestry, different SNP arrays that are transferable between taxa of the same genus, such as Populus, Eucalyptus, Quercus, Picea, Araucaria, Pinus and Pseudotsuga have been developed [87-93] (Table 1). For example, a $50 \mathrm{~K}$ Axiom array, developed from the genome of Picea abies (L.) H. Karst., can be applied to at least four species of Picea, while EUChip60K has been applied to more than 14 taxa of the genus Eucalyptus [81]. The numbers of SNPs detected in coniferous and hardwood species have been relatively similar, but conifers tend to have considerably larger genomes [94], which implies that SNP arrays developed in conifers could have less genome coverage than those developed for broadleaves.

Table 1. Single nucleotide polymorphism (SNP) arrays developed for forest tree species. Genome size corresponds to the estimated genome size, N-SNP is the number of SNPs contained in each array. The density of markers is expressed as the number of SNPs per $1 \mathrm{Mb}$.

\begin{tabular}{|c|c|c|c|c|}
\hline Species & Genome Size $^{a}$ & N-SNP & Density $(\mathrm{SNP} / \mathrm{Mb})^{b}$ & Reference \\
\hline Eucalyptus spp. & $640 \mathrm{Mb}$ & $60 \mathrm{~K}$ & 93.75 & [81] \\
\hline Populus spp. & $420 \mathrm{Mb}$ & $34 \mathrm{~K}$ & 91.5 & [87] \\
\hline Populus nigra & $400-500 \mathrm{Mb}$ & $12 \mathrm{~K}$ & $24-30$ & [95] \\
\hline Quercus spp. & $950-930 \mathrm{Mb}$ & $7.9 \mathrm{~K}$ & 8 & [89] \\
\hline Picea spp. & $20 \mathrm{~Gb}$ & $7.3 \mathrm{~K}$ and $9.6 \mathrm{~K}$ & $0.4-0.5$ & [88] \\
\hline Picea spp. & $20 \mathrm{~Gb}$ & $50 \mathrm{~K}$ & 2.5 & [93] \\
\hline $\begin{array}{l}\text { Araucaria angustifolia } \\
\text { (Bertol.) Kuntze }\end{array}$ & - & $3 \mathrm{~K}$ & - & [90] \\
\hline Pinus spp. & $20-30 \mathrm{~Gb}$ & $50 \mathrm{~K}$ & $1.6-2.5$ & [91] \\
\hline Pinus radiata D. Don & $20-30 \mathrm{~Gb}$ & $80-49 \mathrm{~K}$ & $2-4$ & [96] \\
\hline $\begin{array}{l}\text { Pseudotsuga menziesii } \\
\text { (Mirb.) Franco }\end{array}$ & $16 \mathrm{~Gb}$ & $28 \mathrm{~K}$ & 1.75 & [92] \\
\hline
\end{tabular}

a Estimated size according to Ramos et al. (2018) [97], Zoldos et al. (1998) [98], Tuskan et al. (2006) [99], Kovach et al. (2010) [100], Zimin et al. (2014), (2017) [101,102], Neale et al. (2017) [103], Myburg et al. (2005) [104]. ${ }^{\mathrm{b}}$ Density estimated according to the N-SNP and Genome size.

\section{Genomic Selection/Prediction, an Extension of BLUP Methods to Maximize the Predictive Power of Traits of Interest}

After the emergence of molecular markers on a large scale and the decrease in costs associated with genomic tools, breeders began to use DNA markers to support selection cycles. In general, genomic-assisted breeding can be based on MAS or genomic prediction/selection [105-107]. The efficiency of each of the methods varies according to the genetic architecture underlying the trait under study. MAS estimates the genotypic value of an individual from the effects of selected molecular markers and it has greater effectiveness in phenotypic traits that have an oligogenic genetic architecture [107]. GS is a preferred method when studying complex traits that are affected by a large number of 
genes and are highly influenced by the environment. In the case of forest trees, several QTLs related to various traits of interest have been identified and mapped in association studies, such as growth [108-111], flowering components [112-114], pulpability [115-117] and wood properties [110,118-121]. However, effectively, the application of MAS in traits with polygenic inheritance has been limited. In this sense, it is worth mentioning that the important traits of a forest plantation, such as growth, are controlled by many genes that each contribute little to the phenotypic variation [51,109].

GS was first proposed by Meuwissen et al. (2001) [105] in the context of animal breeding as a method to specifically increase the efficiency of dairy cattle breeding programs. GS was born as an alternative to conventional BLUP based on pedigree information. Unlike in MAS, in GS the effects of thousands of molecular markers are predicted simultaneously, even though these are not individually significant for a trait. According to Daetwyler et al. (2013) [122], GS can widen the range of genetic gain since the individual genetic merits are estimated with greater precision. Although GS does not allow us to identify the function of a gene controlling a trait, the predictive models provide a short-term selection criterion of those individuals who have a better throughput. Moreover, GS has helped us understand the genetic architecture of phenotypic traits and even to implement ecological restoration and biological conservation plans [123,124]. The most widely known GS methods incorporate models derived from the so-called Bayesian alphabet: Bayes A, Bayes B, Bayes $C \pi$, Bayesian ridge regression (BRR), Bayesian least absolute shrinkage and selection operator (LASSO) $[105,125,126]$ and the conventional methods of genomic BLUP (GBLUP) [127] and ridge-regression BLUP (RR-BLUP) [105]. RR-BLUP and GBLUP assume that the markers have the same variance and that each marker makes a small contribution to the prediction model (infinitesimal model). The prediction via GBLUP is performed similarly to that via BLUP, the difference being that the BLUP pedigree matrix is replaced by a relationship matrix constructed from molecular markers. RR-BLUP is a multiple regression method in which the markers are thousands of regressors that explain the variation in a phenotypic trait. In the context of the RR-BLUP method, the breeding (genomic) value of each individual is defined by the following formula [128]:

$$
G E B V_{j}=\sum_{i}^{n} Z_{i j} \hat{m}_{i}
$$

where $n$ corresponds to the total number of markers, $\hat{m}_{i}$ is the estimated effect of the $i$ th marker and $Z_{i j}$ corresponds to the design matrix associated with the vector of the effects of the markers, which encodes the genotype of the $j$ th individual at the $i$ th marker. The abbreviation GEBV stands for genomic estimated breeding value.

In contrast, the Bayes A, Bayes B and Bayesian LASSO methods assume that each marker has its own variance, and the phenotypic variance is explained by loci with effects of different magnitudes [129]. These Bayesian methods are differentiated by the prior distributions that are established and the degree of fit chosen. A more detailed description of each method can be found in Heslot et al. (2012) [130] and De Los Campos et al. (2013) [131]. For example, the Bayesian LASSO method assumes that the effects of the markers are distributed a priori according to a double exponential $(D E)$ distribution: $p\left(m_{i} \mid \lambda, \sigma_{\varepsilon}^{2}\right)=D E\left(m_{i} \mid 0, \lambda / \sigma_{\varepsilon}^{2}\right)$, where $\lambda$ is a regularization parameter. The $D E$ distribution generates a strong contraction (close to 0 ) to estimate the effects of the markers. BRR is a Bayesian method that is based on the model's regressors (whether SNPs or other markers), which have a common variance $\left(\sigma_{m}^{2}\right)$, so that those regressors with the same allelic frequency explain the same proportion of the additive variance and have the same contraction effect [132]. The a priori distribution of the marker effects $\left(m_{i}\right)$ is Gaussian, and $\operatorname{Var}\left(m_{i}\right)$ takes a single value of $\sigma_{m}^{2}$. In the Bayes A model, it is assumed that each marker $\left(m_{i}\right)$ follows an independent normal prior distribution with mean 0 and variance $\sigma_{m_{i}}^{2}$, while the variance of each of them is assumed to be distributed as $\sigma_{m}^{2} \mid v, S^{2} \sim \chi^{-2}\left(v, S^{2}\right)$, where $S^{2}$ and $v$ are the parameters for scale and degrees of freedom, respectively. On the other 
hand, the Bayes B and Bayes C methods include the parameter $\pi$, which corresponds to the probability that the effect of a marker is equal to 0 . For the parameter $\pi$, an a priori distribution $\pi \sim \beta\left(p_{0}, \pi_{0}\right)$ is assumed, such that $p_{0}>0$ and $\pi_{0}$ can take values between 0 and 1 [133]. In both Bayes $B$ and Bayes $C$, the effects of the markers have an a priori normal mixture distribution, such that $m_{i} \mid \pi \sim(1-\pi) N\left(0, \sigma_{m_{i}}^{2}\right)+\pi N\left(0, \sigma_{m_{i}}^{2}=0\right)$. On the one hand, in the Bayes $\mathrm{C} \pi$ method, it is considered that all the markers have a common variance and this variance is distributed in a similar way as in the BRR method, while for the Bayes B method, the variance of the markers follows a similar distribution to that in Bayes A.

In practice, it is recommended to test all available GS methods [134], which should be contrasted in terms of their accuracy or predictive ability. However, if the researcher has an idea of how many loci explain the variation of a trait, he could use a particular method. For example, the Bayes B model bases its analytical assumptions on highly heritable traits and whose variation is explained by large-effect loci [134]. On the other hand, Bayes A represents an option for traits that are controlled by a moderate number of genes. Some studies have shown that Bayesian methods are usually more accurate than GBLUP when the training and validation populations are weakly related genetically $[135,136]$.

With computational advancement and algorithms enhancements, artificial neural networks (ANNs) have emerged as an alternative statistical framework and have gained increasing interest in genomic studies [1,137-140]. This method can be particularly useful when the number of unknown variables is much higher than the number of samples (high-dimensional genomic information), since ANNs have the ability to capture nonlinearities, adaptively $[1,141]$. In the context of plant/tree breeding, few approaches have included non-parametric approaches and non-linear functions based on ANN methods. Maldonado et al. (2020) [1], for instance, investigated several genomic selection models to predict several complex traits in breeding populations of Zea mays L. and Eucalyptus globulus Labill., including two Machine Learning (ML) methods, i.e., Deep Learning (DL) and Bayesian Regularized Neural Network (BRNN), both in combination with different hyperparameters. The results showed that DL had a superior performance than GBLUP, BayesA, BayesB, BayesC $\pi$, BRR, BL, RKHS and BRNN, in terms of predictive ability for all traits (tree growth and stem quality-related traits in the case of E. globulus Labill.), confirming the importance of deep learning models in genome-wide studies and crop/tree improvement, which holds promise for accelerating breeding progress. Moreover, PérezRodríguez et al. (2012) [142] found that BRNN and Radial Basis Function Neural Networks (RBFNNs) (non-linear models) had higher predictive accuracy for grain yield and days to heading in wheat and smaller predictive mean-squared error than Bayesian linear regression models. On the other hand, Zingaretti et al. (2020) [143] evaluated the predictive accuracy of linear and DL techniques in two important small fruits or berries: strawberry and blueberry (polyploid outcrossing species) and did not find an advantage of DL over linear model methods BL and BRR, except when the non-additive component (epistasis) was important. In fact, linear Bayesian models were better than convolutional neural networks for the full additive genetic architecture, whereas the opposite was observed under strong epistasis. Interestingly, Alves et al. (2020) [144] compared GBLUP with ANN in a simulated study considering different levels of dominance effects. They found that ANN had a higher prediction accuracy compared with GBLUP for traits with moderate narrow-sense heritability $\left(\mathrm{h}^{2}=0.30\right)$ and dominance effects of 0 or 0.15 . In this regard, Maldonado et al. (2020) [1] found that the DL approach outperformed GBLUP despite the low dominance effect, confirming that DL is a promising alternative tool for genomic prediction independent on the contribution of additive and/or dominance genetic effects.

In the context of forest tree breeding, GS was originally proposed for the analysis of complex traits such as tree growth and wood-related traits. The main parameter that reveals whether a GS model is adequate for the estimation of genetic merits is the precision and predictive power, which expresses the degree of correlation that exists between the genetic values predicted by the GS model and the adjusted phenotypic values (or adjusted 
breeding values) [145-147]. In the study by Beaulieu et al. (2014) [12], an accuracy of up to 0.435 was obtained in the GS models to predict traits related to wood properties in fir tree. In Pinus pinaster Aiton, Isik et al. (2015) [148] reported that even with a relatively low density of markers, the ability to predict traits related to growth can be moderate (0.43-0.49). The predictive ability of GS models can be increased using different methodological strategies. For example, Cappa et al. (2019) [149] utilized the single-step GBLUP (ssGBLUP) method, for growth and wood-quality traits in Eucalyptus, which consists of simultaneously considering genotyped and nongenotyped trees. According to the authors, the use of additional phenotypic information from nongenotyped trees provided greater predictive ability than GBLUP. Additionally, Ballesta et al. (2020) [150] showed that GS principles can be combined with the GWAS method to increase the ability to predict phenotypic traits with different genetic architectures in Eucalyptus cladocalyx F. Muell.

On the other hand, genomic tools have allowed access to heritable components that cannot be examined through genealogical relationships between individuals [26,151,152]. For example, Müller et al. (2017) [151] determined that the heritability of the diameter at breast height in a population of Eucalyptus pellita F. Muell was too low to calculate (extremely low) by the pedigree method; however, the genomic heritability based on SNPs reached a value of 0.55 (Bayes method B). Table 2 summarizes some of the studies on GS published in the last 5 years on different productive traits in trees.

Table 2. Published studies on genomic prediction (GS) in forest tree species in the last 5 years. Population, N-Markers and Model criteria correspond to the type of population used to implement GS, number of markers and the prediction models, respectively.

\begin{tabular}{|c|c|c|c|c|c|}
\hline Species & Traits & Population & N-Markers & Model & Reference \\
\hline Eucalyptus pellita F. Muell & DBH, HT, VOL & OP & $19 \mathrm{~K}$ & $\begin{array}{c}\text { GBLUP, BA, BB, BC, BL, } \\
\text { BRR }\end{array}$ & {$[151]$} \\
\hline E. pellita F. Muell & DBH, HT, VOL & OP & $2 \mathrm{~K}$ & GBLUP, ssGBLUP & [153] \\
\hline E. robusta $\mathrm{Sm}$. & VOL, LIG, HCEL & Provenance trial & $2.9 \mathrm{~K}$ & RKHS, GBLUP, EN & [154] \\
\hline E. benthamii Maiden \& Cambage & DBH, HT, VOL & OP & $13 \mathrm{~K}$ & $\begin{array}{c}\text { GBLUP, BA, BB, BC, BL, } \\
\text { BRR }\end{array}$ & [151] \\
\hline $\begin{array}{l}\text { E. nitens (H.Deane \& Maiden) } \\
\text { Maiden }\end{array}$ & WD, DBH, TS, GST & $\mathrm{OP}$ & $4.3 \mathrm{~K}$ & GBLUP & [26] \\
\hline $\begin{array}{l}\text { E. nitens (H. Deane \& Maiden) } \\
\text { Maiden }\end{array}$ & DBH, WD, WS, GST, TAS & OP & $9.7 \mathrm{~K}$ & GBLUP & [155] \\
\hline $\begin{array}{l}\text { E. nitens (H. Deane \& Maiden) } \\
\text { Maiden }\end{array}$ & $\begin{array}{l}\mathrm{DBH}, \mathrm{HT}, \mathrm{ST} \text { and } 9 \text { wood } \\
\text { related traits }\end{array}$ & $\mathrm{OP}$ & $12 \mathrm{~K}$ & GBLUP & [152] \\
\hline E. urophylla $x$ E. grandis & HT, VOL, WD, PY, CBH & Go and G1 & $10 \mathrm{~K}$ & $\begin{array}{l}\text { GBLUP, RRBLUP, BL, } \\
\text { RKHS }\end{array}$ & [156] \\
\hline E. grandis $\times$ E. urophylla & VOL, KL, HCEL, Wi, $\delta^{13} \mathrm{C}$ & Clones & $3.3 \mathrm{~K}$ & GBLUP & [7] \\
\hline E. grandis $\times$ E. urophylla & $\begin{array}{c}\text { DBH, VOL, HT, MAI, CELL, } \\
\text { S:G,LIG, WD }\end{array}$ & Full-sibs & $33.4 \mathrm{~K}$ & ssGBLUP, GBLUP & [149] \\
\hline E. grandis & DBH, HT, ST & OP & $2.8 \mathrm{~K}$ & GBLUP multitrait & [157] \\
\hline E. grandis W. Hill & $\begin{array}{c}\text { FL, FW, CELL, S:G, WD, } \\
\text { DBH, HT }\end{array}$ & Full-sibs & $15 \mathrm{~K}$ & GBLUP & [65] \\
\hline E. globulus Labill & BQ, DBH, ST, VOL, HT & Full-sibs and OP & $14 \mathrm{~K}$ & $\begin{array}{l}\text { RRBLUP, RRBLUPB, } \\
\text { BA, BB, BL, PCR, SPCR }\end{array}$ & [13] \\
\hline E. globulus Labill & HT, DBH, ST, BQ, PP & Full-sibs and OP & $14 \mathrm{~K}$ & $\mathrm{BA}, \mathrm{BB}, \mathrm{BC}, \mathrm{BL}, \mathrm{BRR}$ & [36] \\
\hline E. globulus Labill & VOL, WD & Clones & $12 \mathrm{~K}$ & $\begin{array}{l}\text { GBLUP, BL, BB, BC } \\
\text { BRR, BL, BA, BB, BC, }\end{array}$ & [158] \\
\hline E. globulus Labill & PP, ST, HT, DBH, BQ & Full-sibs & $14 \mathrm{~K}$ & $\begin{array}{c}\text { RKHS, GBLUP, DL, } \\
\text { BRNN }\end{array}$ & [1] \\
\hline E. dunni Maiden & DBH, ST & OP & $11 \mathrm{~K}$ & ssGBLUP & [159] \\
\hline E. cladocalyx F. Muell & $\begin{array}{c}\text { HT, DBH, ST, SLD, PP, FI, } \\
\text { BHT }\end{array}$ & $\mathrm{OP}$ & $3.8 \mathrm{~K}$ & GSq, BA, BB, BC, BRR & [150] \\
\hline Picea glauca (Moench) Voss & hat, $\mathrm{DBH}, \mathrm{VOL}, \mathrm{AV}, \mathrm{WD}$ & Polycross, Full-sibs & $4 \mathrm{~K}$ & GBLUP & [160] \\
\hline P. glauca (Moench) Voss & $\begin{array}{l}\text { HT, DBH, VOL, AV, PIC, } \\
\text { PUN, PINC }\end{array}$ & Full-sibs & $4.1 \mathrm{~K}$ & GBLUP & [161] \\
\hline $\begin{array}{l}\text { P. mariana (Mill.) Britton, Sterns \& } \\
\text { Poggenb }\end{array}$ & WD, DBH, HT, MFA & Full-sibs & $5 \mathrm{~K}$ & GBLUP & {$[162]$} \\
\hline P. abies (L.) H. Karst & HT, WD & $\mathrm{OP}$ & $6.3 \mathrm{~K}$ & HBLUP & [163] \\
\hline P. abies (L.) H. Karst & $\begin{array}{l}\text { AV, WD, MFA, DBH, HT, } \\
\text { SLD, WA }\end{array}$ & Polycross & $4 \mathrm{~K}$ & GBLUP, BRR, BC & [164] \\
\hline P. abies (L.) H. Karst & WD, MFA, MOE, AV & $\mathrm{OP}$ & $130 \mathrm{~K}$ & $\begin{array}{l}\text { GBLUP, BB, RKHS, } \\
\text { RRBLUP }\end{array}$ & [64] \\
\hline P. abies (L.) H. Karst & $\mathrm{PP}, \mathrm{AV}, \mathrm{MOE}, \mathrm{HT}$ & Full-sibs & $116 \mathrm{~K}$ & $\begin{array}{c}\text { BLASSO, BRR, GBLUP, } \\
\text { RKHS, BRR }\end{array}$ & [165] \\
\hline
\end{tabular}


Table 2. Cont.

\begin{tabular}{|c|c|c|c|c|c|}
\hline Species & Traits & Population & N-Markers & Model & Reference \\
\hline Pinus contorta Douglas ex Loudon & WD, MFA, HT & Full-sibs and OP & $19 \mathrm{~K}$ & GBLUP, BC & [166] \\
\hline Pinus radiata D. Don & BCF, ST, ICH, ERB & Full-sibs and clones & $67 \mathrm{~K}$ & GBLUP & {$[167]$} \\
\hline Pinus radiata D. Don & ST, DBH, WD, MOE & Full-sibs & $58.6 \mathrm{~K}$ & GBLUP & {$[155]$} \\
\hline Pinus sylvestris Thunb. & HT, DBH, MFA, MOE, WD & Full-sibs & $8.7 \mathrm{~K}$ & GBLUP, BRR, BL & [168] \\
\hline Hevea brasiliensis Muell. Arg & $\mathrm{RB}$ & Full-sibs & $0.3 \mathrm{~K}$ & RKHS, RRBLUP, BL & [169] \\
\hline H. brasiliensis Muell. Arg & $\begin{array}{l}\text { CBH (Two watering } \\
\text { contrasting conditions) }\end{array}$ & Full-sibs & $30 \mathrm{~K}$ & GBLUP & [170] \\
\hline Populus nigra $\mathrm{L}$. & HT, CBH, BF, BS, RST & Clones & $8 \mathrm{~K}$ & GBLUP, BL & [171] \\
\hline $\begin{array}{l}\text { Pseudotsuga menziesii (Mirb.) } \\
\text { Franco }\end{array}$ & JHT & Full-sibs & $70 \mathrm{~K}$ & RRBLUP, GRR, BB & [32] \\
\hline $\begin{array}{c}\text { Pseudotsuga menziesii (Mirb.) } \\
\text { Franco }\end{array}$ & $\mathrm{HT}, \mathrm{WD}, \mathrm{DBH}$ & Full-sibs & $70 \mathrm{~K}$ & RRBLUP, GRR & [172] \\
\hline
\end{tabular}

AV: acoustic velocity; BB: Bayes B; BC: Bayes C; BF: bud flush; BHT: first, bifurcation height; BL: Bayesian LASSO; BQF: branch-cluster frequency; BRNN: Bayesian regularized neural network; BS: bud set; CELL: cellulose content; CBH: circumference at breast height; $\delta 13 \mathrm{C}$ : stable carbon isotope composition; DBH: diameter at breast height; DL: Deep Learning; EN: elastic net methods; ERB: external resin bleeding; FI: flowering intensity; FL: fiber length; FW: fiber width; GRR: generalized ridge regression; GSq: combined method of GS and GWAS; GST: growth strain; HBLUP: genomic and pedigree-derived relationship matrix; HCEL: holo-cellulose; HT: tree height; ICH: internal checking; JHT: juvenile height; KL: Klason lignin; LIG: lignin content; MAI: mean annual increment; MFA: microfibril angle; MOE: modulus of elasticity; OP: Open-pollinated; PCR: principal components regression; PIC: picein concentration in needles; PICN: piceol concentration in needles; PP: pilodyn penetration; PUN: pungenol concentration in needles; PY: pulp yield; RB: rubber production; RKHS: Reproducing Kernel Hilbert Spaces; RRBLUPB: RRBLUP with variable selection procedure; RST: resistance to rust; S:G: syringyl and guaiacyl ratio; SLD: slenderness; SPCR: Supervised PCR; ssGBLUP: single-step GBLUP; ST: stem straightness; TAS: tangential air-dry shrinkage; VOL: volume; WA: weevil attack; WD: wood density; Wi: intrinsic water use efficiency; WS: wood stiffness.

\section{Factors That Determine the Accuracy of Genomic Prediction Models in Forest Trees}

Above, it was discussed how the accuracy of genomic prediction methods changes according to the analytical assumptions that support each method. However, genetic factors that are specific to breeding populations determine the effectiveness of genomicassisted selection. The existing pattern of LD in a given breeding population is one of the main factors that determines the power of genomic tools to predict phenotypic traits because the extent of LD throughout the genome of a species determines the density of markers that is necessary for accurate prediction $[23,24]$. Strictly speaking, if the LD spreads across relatively large genomic distances, a lower density of markers could be necessary because it increases the probability of detecting markers that are in LD with QTLs. In contrast, if LD decreases within a relatively short genomic distance, a higher density of markers would have to be used to obtain a more accurate prediction.

The magnitude of LD in a population comes from the history and dynamics of the population [173]. In general, the LD in populations of cross-pollinating plants (such as most species of interest for forestry) decreases rapidly as the physical distance between markers increases because the number of effective recombinations is relatively higher than in self-pollinating species. For example, LD ceases to be significant at distances of 3000-6000 bp in natural populations of Populus trichocarpa Torr. \& A.Gray ex Hook. [174] and within a distance of less than $1000 \mathrm{bp}$ in Pinus taeda L. [175] while in self-pollinated species, such as soybeans and rice, the LD can be significant (in some populations) at interlocus distances of 10,000 bp and 25,000 bp, respectively (reviewed by [176]). Additionally, populations of forest species tend to be more heterozygous in their loci due to the reproductive mechanisms that these species have, since they have large effective size, high genetic diversity and low intrapopulation genetic differentiation $[177,178]$.

Natural populations of forest species have lower LD values than cultivated and improved populations [151,158,179-181]. For example, LD in a natural population of Populus can decrease within 750-1000 bp [179,180], whereas in an improved population, LD can extend up to $2500 \mathrm{bp}[181,182]$. In the case of coniferous populations, the disequilibrium can decrease within much shorter genomic distances than for other tree species $(<1000 \mathrm{bp})$. In the case of breeding populations of Eucalyptus, LD can decrease rapidly over $3000 \mathrm{bp}$ or $25,000 \mathrm{bp}[26,36,121,158,183]$, while in populations that have not been subjected to selection, the disequilibrium pattern can decrease within 500 bp [184]. 
Another factor that affects the accuracy of GS is the effective population size $[17,185]$. According to Grattapaglia and Resende (2011) [186], the effective size is inversely proportional to the level of accuracy of the GS model. For example, if it is desired to predict a phenotype controlled by 50 QTLs, with an effective size of 100 individuals and a density of 2 markers $/ \mathrm{cm}$, a predictive value of 0.36 is estimated, which can be increased to 0.8 if we have a density of 20 markers $/ \mathrm{cm}$. However, with an effective size of 10 individuals, under these same conditions, the predictive power can be increased from 0.73 to 0.88 , which shows that small effective sizes allow us to increase the predictive power of a model, especially with a low density of markers.

In this same context, both in GS methods and in pedigree-based prediction, the predictive accuracy of the phenotype of an individual depends on how accurate the estimation of the genetic relationships between the individuals of the population is $[15,16]$. The predictive power of a GS model can be increased if the individuals who are used as references to estimate the additive effects of the loci (training population) are genetically related to the individuals whose phenotype is to be predicted (validation population) $[17-19,187]$. The genetic structure of a population is a factor that influences the degree of precision that a genomic prediction model can have $[26,156,188-190]$. The genetic structure of a population is defined by the degree of kinship that exists between the individuals who make up the population, which can be established by the genealogical background, or by genomic data. In the case of individuals who come from a natural population, the genetic structure can be given by the genealogical background and by the existence of subpopulations (genetically differentiated groups) within the same population. For example, Tan et al. (2017) [156] showed that the prediction of some traits in Eucalyptus hybrids could be favored by using a training population that is closely related to the validation population in terms of pedigree and population genetic structure. In contrast, if the training population is composed of individuals genetically distant from the validation population, the predictive ability can be reduced by up to $25 \%$.

The determination of kinship relationships between individuals or organisms has been an important aspect in several fields of knowledge, such as forensic science, conservation genetics and animal and plant breeding [27]. Estimates of kinship between individuals are traditionally based on pedigree data, in which it is assumed that those individuals who act as founders of populations (for example, families) are not genetically related [191]. If the individuals of a population are genotyped, the polymorphic loci which are shared may be identical by state (IBS) or identical by descent (IBD), depending on whether these loci were inherited from the same ancestor. It is expected that individuals who share the same parental lines (full siblings) have on average 50\% alleles that are IBD. However, the percentage of the genome they share is subject to variation due to random events that may occur. In this sense, genetic relationships based on pedigrees are arbitrary and theoretical; therefore, they are not necessarily a reflection of the real way in which genomes are inherited. Despite this drawback, pedigree data have been widely used to establish relationships between individuals of a population in quantitative genetics research [191]. Based on this problem, VanRaden (2008) [127] proposed making predictions via BLUP using molecular markers (SNPs) to determine kinship relationships within a group of individuals instead of by using the pedigree matrix (this method later came to be known as GBLUP). Additionally, Yu et al. (2006) [192] proposed using marker-based relationship matrices as covariates in GWAS models. SNP biallelic markers do not have enough information at the individual level, so some studies suggest that a high density of markers is required to establish reliable genealogical relationships [193,194]. Additionally, in populations with multiple founders, generations and few descendants, genotyping errors are difficult to detect $[195,196]$. An alternative for kinship analysis is the identification of haplotypes [27-29]. When two or more loci have a low probability of recombination between them, combinations of alleles called haplotypes are formed [197,198], which are genomic regions within a chromosome that tend to be inherited in joint form [199-201]. In this context, Edwards (2015) [27] proposed evaluating the kinship between individuals 
based on the construction of haplotypes present in the study population. According to this same author, these kinship relationships can estimate more precise genealogical relationships than the VanRaden relationship matrix [127]. If one wants to know the intrapopulation coancestry, it is most advisable to use haplotypes that are IBD. However, haplotypes can have both IBD and IBS relationships.

\section{The Detection of Alleles in Narrow LD Allows the Optimization of the Accuracy of Genomic Prediction Models}

Several studies have evaluated the predictive power of phenotypic traits in GS models that include haplotypes from SNP arrays [35,202-206]. One of the advantages of using haplotypes in GS is the ability to detect mutations [205]. According to Curtis et al. (2001) [207], when mutations have occurred, it is possible that the allele frequencies will remain (almost) unaltered. However, when haplotypes are analyzed, mutations in different loci tend to cause important changes in haplotype frequencies. Therefore, a QTL that is not in complete LD with an individual marker may be in complete LD with a specific haplotype. Moreover, haplotype-based approaches can include epistatic effects, in addition to additive effects $[208,209]$, which is of interest in forest tree breeding (for example, in clonal selection and in the dissection of adaptive traits [4,210]. Additionally, the use of haplotypes, instead of individual markers, reduces the degrees of freedom in the prediction or genomic-association models, which contributes to greater accuracy in the detection of QTLs [192]. An also relevant aspect is the size of a haplotype found in a given population. The longer the haplotype (greater number of SNPs in LD), the fewer the effects that must be estimated, which leads to more precise estimates [211] and they are simpler to handle computationally.

The predictive power of haplotypes and molecular markers (individually) could depend on the trait that sought to be improved. In the context of animal breeding, some authors suggest that the haplotype approach may be especially beneficial for predicting traits of relatively high heritability $[205,212,213]$. However, in plants, prediction based on haplotypes has been especially beneficial for predicting low-heritability traits $[31,33,34]$. For example, Matias et al. (2017) [31] reported that the predictive accuracy of the models based on haplotypes was higher than the accuracy based on SNPs (not grouped into haplotypes) at predicting the yield of corn grains, but this result was not observed in the genomic prediction of plant height. According to these same authors, the yield of maize grains has low genetic control compared to the height of the plant. In the context of forest species, Ballesta et al. (2019) [36] showed that genomic prediction based on haplotypes can be an especially suitable approach for traits with low genetic control $\left(\mathrm{h}^{2}<0.1\right)$ in Eucalyptus globulus Labill.

Villumisen and Janss et al. (2009) [35] showed, through simulated data, that genomic predictions based on haplotypes are especially beneficial for traits with low genetic control (relatively low heritability), in which haplotypes formed by five SNPs in LD have better goodness of fit and predictive power than models based on markers not grouped in haplotypes. According to [214] the use of haplotypes permits evaluations at the multiallelic level, which lead to a better representation of the variability associated with the traits with low heritability, which are generally controlled by several QTLs of relatively small effect. In this context, haplotypes would allow access to heritable components of certain phenotypic traits that cannot be captured by SNPs. The effectiveness of the haplotype approach in GS depends on how the haplotypes are defined in the study population [31,205]. For example, a haplotype can be defined according to a certain number of polymorphic loci, a defined size (genomic distance), or according to an LD threshold value. It is common for haplotypes to be defined by a certain number of SNPs [30,35]. Since this approach does not consider the LD between the markers and the historical recombination events of the population, some genetic background may not be considered in quantifying the variability between individuals [205].

Some studies suggest that GS based purely on molecular markers can lead to a loss of genetic variability, which leads to an increase in the rate of inbreeding [215-218]. For 
example, Rutkoski et al. (2015) [215] showed that the genetic gains for rust resistance in wheat obtained by GS and phenotypic selection are equivalent; however, GS generates a faster reduction in genetic diversity (per year) than phenotypic selection. In a simulated study, Lin et al. (2016) [216] reported that GS would double and triple the genetic gains of persistence and throughput of Lolium perenne L. with respect to phenotypic selection, respectively. However, GS led to a higher rate of inbreeding per selection cycle than phenotypic selection. This compromise between genetic gain and loss of diversity has not been a focus of study in forest species; however, it is also expected that GS can cause a significant loss of genetic diversity compared to traditional schemes that use phenotypic selection [219]. In this sense, several studies have proposed different strategies to establish a balance between genetic gains and post selection conserved diversity [183,219-221]. According to Daetwyler et al. (2015) [122], GS based only on SNPs could generate the loss of certain deleterious alleles (or those that apparently have no effect on the phenotype) from the population; however, haplotypes allow us to manage a selection based on alleles that do or do not have effects but remain in LD. In this sense, GS based on haplotypes could also contribute to good management of genetic resources in such a way that genetic gains could be obtained without sacrificing genetic variability.

Haplotype-based GS has been mainly implemented in agricultural crops and selfpollinated plants (for example, wheat; [33], where high LD values can be found throughout their genomes, which favors the identification of haplotypes in a population. In crosspollinated plants, such as forest species, LD usually decreases within short genomic distances, which allows the identification of smaller haplotypes made up of fewer alleles. In this sense, the use of haplotypes in the GS of forest species could be restricted by the genotyping density of the population. On the other hand, Mora-Poblete et al. (2021) [3] showed that a low density of SNPs and consequently of haplotypes, could be compensated for by the combined use of GS and the principles of GWASs. In E. cladocalyx F. Muell, the authors reported that the genomic predictive ability of cyanogenic glycoside and anthocyanin contents, based on haplotypes, can be improved by the use of haplotypes significantly associated with these quantitative traits

\section{Genome-Wide Association Studies (GWAS)}

High-throughput genotyping technology and phenotyping platforms have enabled large-scale marker-trait association analysis, such as GWAS, to precisely dissect the genetic architecture of plant traits [222]. In trees, several studies have reported many putative genomic regions associated with variation of related-traits to tree phenology [223,224], wood properties $[118,120,165,225-229]$, growth (i.e., wood volume, tree height and diameter; [108,111,117,120,226,230-232], resistance to pests and diseases [233-236], among others. For example, McKown et al. (2018) [223] implemented a GWAS analysis with the motivation to understand the molecular mechanisms of the variation in bud-break of flowers in Populus trichocarpa Torr. \& A.Gray ex Hook. The authors identified $\sim 30$ polymorphisms within 16 annotated genes in the Populus trichocarpa genome, which were mainly associated with meristem growth, bud activation, cell expansion and proliferation, cold acclimatization and heat response. Recently, Elfstrand et al. (2020) [236] reported eleven marker-trait associations (MTAs) associated with the resistance to Heterobasidion parviporum in Picea abies (L.) H. Karst., which explained between 2 and $5 \%$ of the phenotypic variation of the studied trait. Additionally, the authors demonstrated that the PaLAC5 gene, one of the candidate genes related to resistance to $H$. parviporum, could be involved in the development of the length of the lesion, as an induced defense response. Bai et al. (2019) [231] identified 29 nuclear collections from $~ 150$ Pinus massoniana Lamb. trees, which were evaluated for different phenotypic traits. They found a large number of SNPs significantly associated with resin production, wood volume, tree height and diameter. In general, many marker-trait associations with relatively large effect have been detected for wood properties, disease resistance and phenology [237]. 
GWASs have been carried out considering different analysis strategies, which are often complemented with studies of gene co-expression networks, transcriptomic studies, heterologous expression assays, among others. For instance, Valenzuela et al. (2021) [111] identified $\sim 90$ SNPs and haplotype blocks associated with growth and stem quality traits in E. cladocaly $x$ F. Muell under arid conditions, 11 of which were common between tree height, wood hardness and diameter; a result consistent with the trade-off between hydraulic safety and efficiency in Eucalyptus trees under drought conditions. Interestingly, the significant SNPs and haplotype blocks were located close to genes involved in the primary metabolism, biosynthesis of cell wall components and stress response genes, which could be related to the mechanisms of adaptation to stressful conditions. Lamara et al. (2016) [225] developed an integrative approach that involves association mapping results and co-expression networks in white spruce trees (Picea glauca (Moench) Voss). In this study, the authors tested SNPs into 2000 candidate genes for statistical associations with microfibril angle, wood density, stiffness and ring width. The co-expression networks revealed complex interactions and pleotropic effects between genes involved in wood stiffness and microfibril angle. Baison et al. (2019) [238] performed a GWAS for several wood-related traits in Picea abies (L.) H. Karst., using 170 K SNPs generated from exome genotyping of mother trees. The authors identified more than 50 SNPs associated with 39 candidate genes, of which their role in wood formation and tree growth has previously been recognized. Moreover, to understand the genetic mechanisms underlying wood anatomical and morphological traits in Populus trichocarpa Torr. \& A.Gray ex Hook., Chhetri et al. (2020) [228] performed a functional enrichment analysis on coexpression nearest neighbors for gene models by the wood anatomical and morphological trait GWAS analyses. The results evidenced that the genes affecting cell wall composition and transport related genes were enriched in wood anatomy and stomatal density trait networks. Signaling and metabolism related genes were also common in networks for stomatal density. They concluded that the identified genes provide further insights into the genetic dissection of wood anatomical and morphological traits in Populus, which are important determinants of the suitability and sustainability of improved genotypes for lignocellulosic biofuel production.

Muchero et al. (2018) [234] employed a GWAS strategy to identify putative loci associated with the resistance to the invasive fungal pathogen Sphaerulina musiva in Populus trichocarpa Torr. \& A.Gray ex Hook. About 90 SNPs encompassing 73 candidate genes were significantly associated to the number of cankers, number of cankers $\mathrm{cm}^{-1}$ and disease severity based on digital imagery. Interestingly, three loci were functionally validated by a transcriptomic study, allele analysis, binding assays and overexpression assays. Recently, Quan et al. (2021) [229] performed a combined approach that includes GWAS, transcriptomic analysis and transgenic experiments to dissect the genetic architecture of wood properties and photosynthesis in Populus tomentosa C.K. Schneid. The authors detected SNPs related to $\sim 170$ candidate genes for the studied traits, 74 epistatic relationships between the phenotypes and several pleiotropic loci. In addition, the heterologous expression of two pleiotropic genes in Arabidopsis thaliana (L.) Heynh. (i.e., PtoMYB62 and PtoMYB80) demonstrated that these genes control the regulatory networks of photosynthesis and the components of the secondary wall, respectively, in P. tomentosa.

In terms of new challenges to implementing the integration of different OMICs technologies, Du et al. (2018) [239] discussed about the challenges and prospects of GWAS to improve wood properties in major timber species, including Eucalyptus, Populus and various coniferous species. The authors summarized the recent progress in GWAS-based functional genomics of these traits and concluded that the emerging high-throughput phenotyping technology will be broadly used in the future to collect data for quantitative studies of complex traits related to tree growth, adaptation, morphological and physiological traits.8. Genome editing in forest trees

The anticipated expansion of the population in the coming decades will significantly boost demand for forest products. Due to the long juvenile period and genomic complexity of forests trees, the genetic improvement via conventional breeding is laborious and 
time-consuming. Therefore, genetic modification (GM) provides the potential for transformation in shorter timeframes but is challenged by existing genetically modified organism (GMO) laws. Genome editing (GE), which may generate mutations in sites, allows for the fast implementation of specific changes and is less restricted worldwide than genetically modified technology $[240,241]$. Genome engineering in forestry is urgently needed given the rise in human activity and the effects of climate change (for instance, changes in rainfall distribution and the increase in severe droughts). Based on many field investigations, GE technology strengthens wood products from intensively cultivated planted trees. It may be especially relevant given the rapid increase in biotic and abiotic stress on forests [242,243].

GE techniques such as Zinc Finger Nuclease (ZFN) and transcription activator-like effector nuclease (TALENs) may be used to modify the genome. However, these methods are either labor demanding or prohibitively costly since the targeting mechanisms are all dependent on protein-nucleic acid interactions, necessitating creating a unique protein for each gene locus of interest [244]. Recent advancements in understanding prokaryotic adaptive immune systems provide another approach for genome editing named clustered regularly interspaced short palindromic repeats and CRISPR-associated protein 9 (CRISPR/Cas9). It is a highly efficient and effective genome editing technique that has been used to effectively implement targetable changes at specific places in the genomes of forest trees [245-248]. The Doudna group revealed the primary mechanism through which Cas proteins and CRISPR arrays functioned in 2012 [249]. CRISPR/Cas9 is a more versatile method among other genome engineering tools like Zinc Finger Nuclease (ZFN) and transcription activator-like effector nuclease (TALENs) [250].

This method enables editing single to many genes by knock-in or knock-out genes from the host genome. Thus, various traits may be introduced or metabolic pathways modified concurrently by inserting double-stranded breaks (DSBs) at multiple locations [251-253]. The other most important aspect about the use of site-directed mutagenesis in plants is that it is relatively inexpensive, effective and easy to apply compared to other techniques $[246,254]$. CRISPR was also successfully used by targeting potential development and biosynthesis pathway genes in grapes as well as in the tropical tree Parasponia andersonii Planch $[255,256]$. Although CRISPR/Cas9 applications are expected to begin with economically significant agricultural plants, the growing number of undescribed species whose whole genomes are being sequenced will enable the technique to be used more widely throughout the plant kingdom. The pipeline to adapt the CRISPR in forest tree is given in Figure 1.

Most significant progress has been achieved in woody species to date with poplar, which was the first stably transgenic tree to be genome-edited with high efficiency using the CRISPR/Cas9 system $[257,258]$. The first time CRISPR/Cas9 has been used for biallelic mutations in woody perennials [259]. Four members of the 4-coumarate: CoA ligase (4CL) gene family were targeted in Populus using CRISPR/Cas9 genome editing. One of the genes from the $4 C L$ family is known as the $4 C L 1$ gene and it has been widely studied for its role in lignin production (Table 3). The lignin content of all edited transgenic plants was decreased by about $23 \%$, with a corresponding reduction in the S/G lignin ratio of around $30 \%[257,259,260]$. Furthermore, the CRISPR/Cas9 technology was also used to alter the genome of Populus tomentosa Carr. It was shown that a protospaceradjacent motif (PAM). is followed by four guide RNAs (gRNAs) that target the phytoene desaturase gene 8 (PtoPDS-8) in poplar through Agrobacterium-mediated transformation and albino phenotype were observed in homozygous plants. Researchers found that mutation efficiency at these target locations was assessed to be $51.7 \%$ based on RNAguided genome editing events and suggesting that CRISPR/Cas9 is efficient method to edit the genome of woody plants $[248,259]$. Most CRISPR studies have been addressed phenylpropanoid metabolism and/or cell wall properties in poplar. CRISPR-knock out (CRISPR-KO) of MYB transcriptive factors either raised the flow of phenylpropanoid (PtoMYB156 and PtrMYB57) or reduced the flow (PtoMYB115 and PtoMYB170), influencing the lignin deposition (PtoMYB156 and PtoMYB170) [261,262]. CRISPR-KO mutants showed 
a brassinosteroids biosynthetic gene, which was similarly affected by secondary wall synthesis, indicating the involvement of brassinosteroids in the development of wood [263].

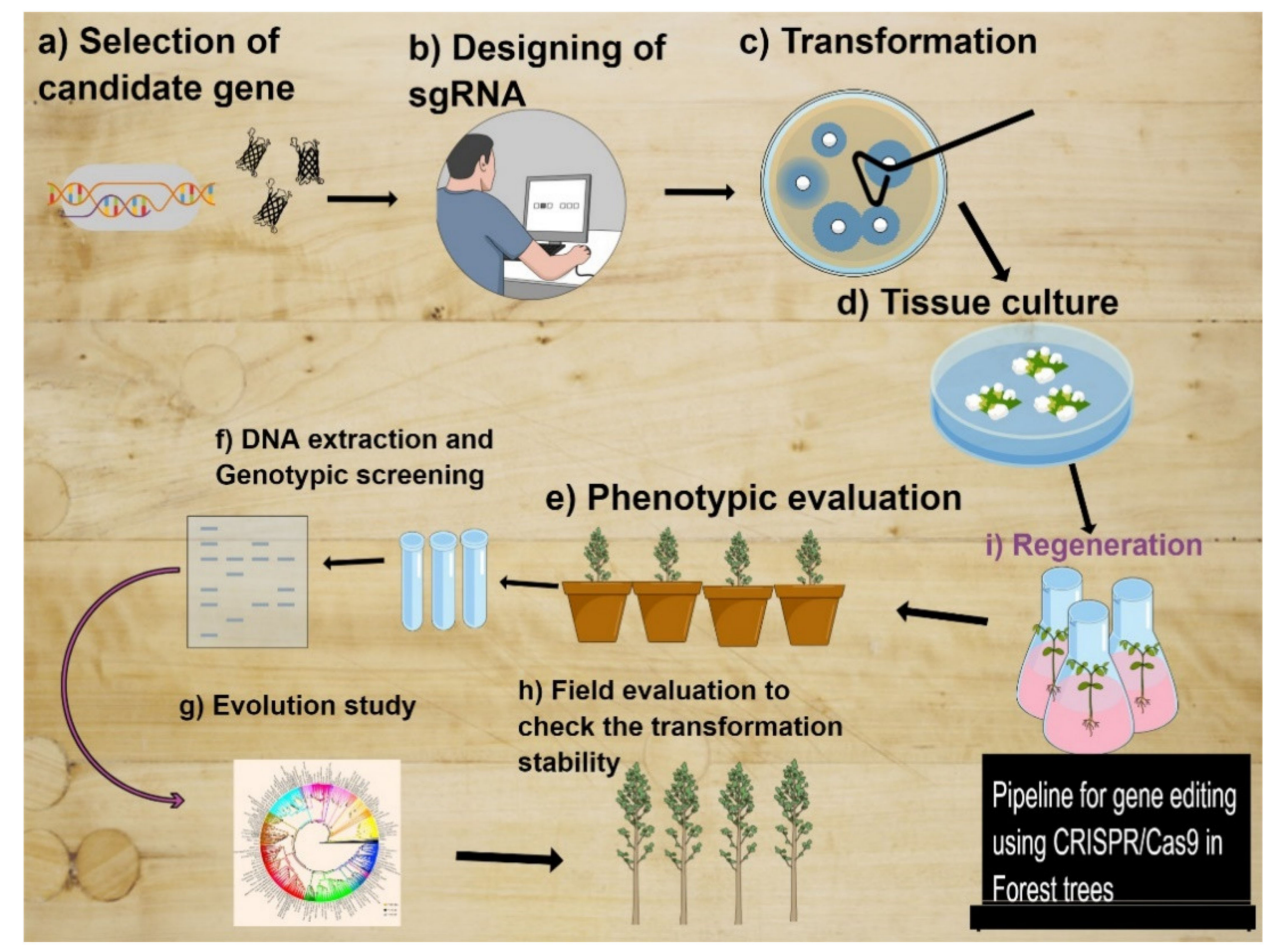

Figure 1. The pipeline of CRISPR/Cas9 to develop the transgenic plants in a forest tree. (a) Selection of candidate gene according to the trait under selection. (b) Design of the target on the gene sequence using any available online tool for sgRNA designing. (c) Construction of vector and transformation of cas9 vector into the explant through agrobacterium mediated transformation. (d) Develop the transgenic plants by tissue culture and regeneration of plant from the explant. (e) Regenerated plants are grown under glasshouse conditions to check the phenotypic according to the proposed objective. (f) Extract the DNA for genotypic analysis of plant carry mutation either homozygous or heterozygous or mutation didn't occur. This step can be performed before phenotypic evolution. (g) On this step, check the evolutionary study if necessary, according to the trait under selection. (h) Choose the best plant based on phenotype as well on genotypic analysis for field evaluation.

Additionally, CRISPR/Cas9 works very well and accurately in two poplar clones to produce $L E A F Y(L F Y)$ and AGAMOUS (AG) mutations through a transgenic approach. A distinct mutation spectrum was observed $L F Y$ and $A G$ in sgRNA-gene combinations. While an AG-sgRNA construct containing two sgRNAs produced comparable mutation spectra between two poplar clones, an LFY-sgRNA construct containing a single sgRNA produced substantially different mutation spectra between the same two clones [241]. Similar genetic studies were applied on Eucalyptus [264]. CRISPR Cas9 was used to produce transgenic plants in the Eucalyptus orthologue of LFY by converting a Eucalyptus grandis x urophylla wild-type hybrid and two Flowering Locus T (FT) overexpressing lines targeting the LFY orthologues of ELFY. The CRISPR-KO mutants achieved 100\% transgenic insertion such as deletion, frameshift mutation and phenotypically transgenic plants as the absence of male and female gametes and indeterminacy in floral development due to floral alteration because of disruption of ELFY function. Similarly, Van Zeijl et al. (2018) [256] presented a quick and effective technique for Agrobacterium tumefaciens-mediated transformation and CRISPR/Cas 9 mutation within 03 months in the fast-growing tropical tree species Parasponia andersonii Planch. They edited the four genes PanHK4, PanEIN2, PanNSP1 and PanNSP2 that regulate cytokinin, ethylene, or strigolactone hormonal pathways and, in legumes, perform important symbiotic activities. CRISP-KO mutants of PanHK4 and 
PanEIN2 reduced the procambium activity and disturbed sex differentiation, respectively. In contrast, CRISP-KO mutants of PanNSP1 and PanNSP2 were essential for nodule formation. Using CRISPR/Cas9, forest tree genomics may be taken to the next level by evaluating gene function and its role in adapting trees to their environment $[247,265]$. Multiple DNA repair pathways may be involved in CRISPR/Cas9-induced mutations, according to published tree studies. These studies suggest that the sequence context at or near the target sites may affect mutagenesis results. Available findings indicate persistent CRISPR-induced mutations and related phenotypes across many clonal generations enabling commercial production of elite trees propagated vegetatively [240,258,266].

Furthermore, in recent years, Landstrasse and Grosshansdorf (2019) [267] checked the efficiency of sgRNA in a poplar species (Populus tremula L.) using CRISPR/Cas9. They selected twelve genes for three distinct study areas, including SOC1, FUL, their paralogs, four NFP-like genes and TOZ19. The sgRNAs were created for editing with Cas9 nuclease and transferred into P. tremula L. and regenerated plants showed different types of editing, with single nucleotide insertions being the most common occurrence. They attempted to establish a correlation between genome editing and gRNA efficiency by evaluating the genome editing effort. They suggested that the GC content, purine residues in the final four nucleotides of the gRNA and an at least partially unpaired seed region all affected the gRNAs effectiveness for target cleavage $[267,268]$. Similar study has done an in Pinus radiata D. Don using CRISPR/Cas9. They explored the use of this system to edit the xylan 1 (GUX1) gene in P. radiata D. Don and showed genome editing using DNA and RNPs [269]. They concluded that CRISPR/Cas9 can generate biallelic and monoallelic INDELs in the coniferous tree $P$. radiata D. Don using DNA and RNPs, respectively. This study enables the use of genome editing in conifers to change the desired traits, or attributes, quickly.

Toxic diseases are causing just as much damage in forest plantations. They are a worldwide concern for forest ecosystems and must be handled as soon as possible. Ideally, CRISPR/Cas9 should be integrated into forest development projects to create more effective disease resistance methods for long-term forest sustainability [240]. For example, using CRISPR/Cas9 to combat Dutch elm disease (DED) pathogen Ophiostoma novo-ulmi is another intriguing potential, in which it has been demonstrated that these genes are excellent candidates for CRISPR/Cas9 gene editing to generate knockout mutants with decreased capacity to switch the DED pathogen throughout the elm tree life cycle $[270,271]$. Due to their lengthy vegetative life and poor seed laying rates, it is challenging to produce homozygous mutants via self-pollination in many forest tree species. Ding et al. (2020) reported a feasible method to decrease the incidence of chimeric mutant poplar trees with CRISPR/Cas9 with the second round of shoot regeneration utilizing leaves as the explants. A total of 15 transgenic plantlets were screened for homozygous mutants of PdbPDS1. Only one was found, which was confirmed by both phenotypic and genotypic analysis; in T0 generation, all transgenic plants were chimeric. Still, during the second round of shoot regeneration, about 27.0 percent or 19.1 percent of the regenerated shoots were homozygous mutants with or without kanamycin selection, respectively.

Despite the advancement in genome editing, CRISPR/Cas9 has limited use in the formation of transgenic forest trees. Recently, CRISPR/Cas12a is a newly developed novel CRISPR effector protein supporting the CRISPR/Cas to edit the larger genome fragments. Two popular species, such as Populus alba L. and Populus glandulosa Moench were subjected to CRISPR/Cas12a to achieve targeted mutations using three nucleases AsCas12a, AsCas12a and LbCas12a. It has been utilized in using CRISPR/Cas12 to knock off various targets of the PDS gene. AsCas12a is a more appropriate and efficient method to edit the big part of the genome at editing sites with the most remarkable mutation. For multi-gene knockout mutation in forest trees, the advantages of CRISPR/Cas12a for the creation of transgenic tree species are only further amended. A method for forest genetics for developing transgenic tree species will be provided using CRISPR/Cas12 [272]. There are still specific issues for the developing transgenic trees due to their longer life span and vegetative growth developmental stages. In woody perennials, CRISPR-based 
transformations in the behavior of trees to grow under different sets of environments, growth acceleration for the production of wood, nuts and barriers are much needed in the modern era [273].

\section{GRF-GIF Chimeras Could Be Gamer Changer Tools in Forest Editing to Boost Tree Regeneration}

Low plant regeneration efficiency and few transformable genotypes restrict the potential of genome editing to enhance the performance of crops and forest trees [264,266]. Genetic engineering of woody plants has many challenges, including poor transformation efficiency, a lack of knowledge on optimum expression cassettes and difficulty isolating clonal-modified plants [274]. Additionally, low regeneration efficiency limits the plant material from being transformed. Two independent investigations have showed that GROWTH-REGULATING FACTORs (GRFs) alone or when combined with GRF-INTERACTING FACTOR (GIF) may drastically increase tissue culture regeneration from diverse plant species. In terms of plant transformation and gene editing, GRF-GIF chimeras may be a game-changer for genome editing in dicot species and forest gene editing [275]. Debernardi et al. (2020) [276] demonstrated that the efficiency and speed of regeneration are improved in wheat, triticale and rice using a protein expression that combines GRF4 and GIF1; this leads to an increase in the number of transformable wheat genotypes. Moreover, a combination of GRF4-GIF1 and CRISPR/Cas9 genome editing produced 30 altered wheat plants with mutations in the gene $\mathrm{Q}(A P 2 L-A 5)$. Finally, they demonstrated that a dicot GRF-GIF chimera increases regeneration efficiency in citrus, indicating that this approach may be applied to other dicot crops [277].

According to the study performed by Debernardi et al. (2020) [276], we believe that this strategy will also be helpful in forest gene editing, especially in those trees in which there is no stable transformation method yet and no optimize genotype for transformation through CRISPR/Cas9. For this method, we can prepare a CRISPR/Cas9 construct with the combination of dicot GRF-GIF chimera for any forest tree (e.g., poplar) for the Agrobacterium transformation to generate the transgenic plant. By using this strategy, the researcher can try different types of genotypes to check the regeneration efficiencies. This hypothesis was already proved in wheat, rice and citrus and regeneration efficiencies were high compared to control for detail [275]. The transformation protocol in wheat was reduced and faster with the GRF4-GIF1 chimera five weeks than normal ones. It is suggested that transformation will also be faster in trees. After generated the transgenic tree plants, then grow the transgenic plants under speed breeding protocol to boost up the growth of the plant for the screening of the homozygous or heterozygous plant as well phenotypic evolution [278-281]. Speed breeding is a breeding method that reduces the generation time and speeds up breeding research programs by a considerable amount. Due to the 22-h photoperiod and the temperature control, the generation time has been significantly shortened. As a result of speed breeding, spring wheat (Triticum aestivum L.), durum wheat (T. durum Desf.), barley (Hordeum vulgare L.), chickpea (Cicer arietinum L.), pea (Pisum sativum L.) and canola (Brassica napus L.) may produce up to six generations each year instead of two or three under regular glasshouse circumstances (Figure 2). For detail about speed breeding, see [278-281]). Using these strategies, a researcher can save time to edit the genome of forest trees by CRISPR/Cas9. 


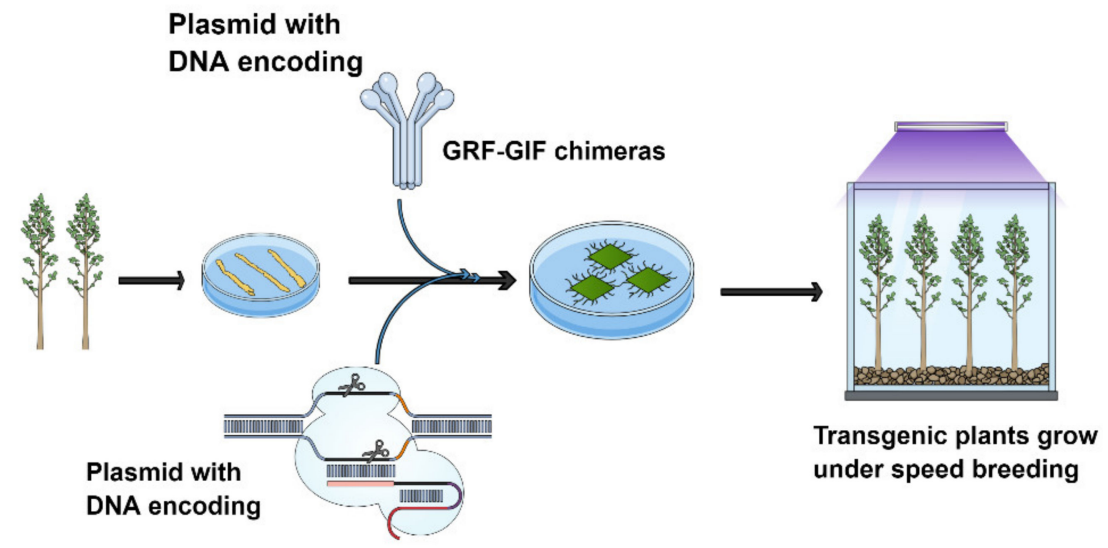

Figure 2. Construction of CRISPR/Cas9 vector with GRF-GIF chimeras to edit the genomes of tree breeding populations. After constructing the vector, do the transformation as per available protocol in the lab with different genotypes. The regenerated plant should be grown under speed breeding protocol to boost the growth period for the phenotypic and genotypic analysis to do further investigation quickly modified by [275].

Table 3. List of tree species successfully transformed genetically and potential candidates to be genome-edited with CRISPR/Cas9 and CRISPR/Cas12.

\begin{tabular}{|c|c|c|c|c|c|}
\hline Tree Species & Method & Targeted Gene & $\begin{array}{l}\text { Transformation } \\
\text { Method }\end{array}$ & Findings & References \\
\hline Populus & CRISPR/Cas9 & $4 C L 1,4 C L 2,4 C L 5$ & AT & $\begin{array}{c}\text { Role in lignin production. The lignin content of all } \\
\text { edited transgenic plants was decreased by about } 23 \% \text {, } \\
\text { with a corresponding reduction in the S/G lignin ratio } \\
\text { of around } 30 \% \text {. }\end{array}$ & [259] \\
\hline Populus tomentosa Carr & CRISPR/Cas9 & PtoPDS & AT & Chlorophyll biosynthesis, albino phenotype & [248] \\
\hline Populus tomentosa Carr & CRISPR/Cas9 & $\begin{array}{l}\text { MYB57, } \\
\text { MYB115, MYB156, } \\
M Y B 170\end{array}$ & AT & $\begin{array}{l}\text { Ectopic deposition of lignin, xylan and cellulose } \\
\text { during secondary cell wall formation }\end{array}$ & [261] \\
\hline Populus tomentosa Carr & CRISPR/Cas9 & $B R C 1-1, B R C 2-$ & AT & $\begin{array}{c}\text { Secondary wall synthesis, which is responsible the } \\
\text { involvement of brassinosteroids in the } \\
\text { development of wood }\end{array}$ & [263] \\
\hline Populus tremula $\times$ P. alba & CRISPR/Cas9 & $A G 1, A G 2, L F Y$ & AT & $\begin{array}{c}\text { A distinct mutation spectrum was observed } L F Y \\
\text { and } A G \text { in sgRNA-gene } \\
\text { combinations }\end{array}$ & [241] \\
\hline $\begin{array}{l}\text { Parasponia andersonii } \\
\text { Planch (tropical tree) }\end{array}$ & CRISPR/Cas9 & EIN2, HK4, NSP1, NSP2 & AT & $\begin{array}{c}\text { Regulate cytokinin, ethylene, or } \\
\text { strigolactone } \\
\text { hormonal pathways and, in legumes, perform } \\
\text { important symbiotic activities }\end{array}$ & [256] \\
\hline Populus tremula $\mathrm{L}$. & CRISPR/Cas9 & SOC1, FUL, NFP TOZ19 & AT & $\begin{array}{l}\text { GC content, purine residues in the final four } \\
\text { nucleotides of the gRNA and an at least partially } \\
\text { unpaired seed region all affected the gRNAs } \\
\text { effectiveness for target cleavage }\end{array}$ & [267] \\
\hline Pinus radiata D. Don & CRISPR/Cas9 & GUX1 & AT & $\begin{array}{l}\text { biallelic and monoallelic INDELs can be generated in } \\
\text { the coniferous tree } P \text {. radiata using DNA and RNPs } \\
\text { Second, regeneration could produce homozygous }\end{array}$ & [282] \\
\hline $\begin{array}{l}\text { Populus davidiana } \times \\
\text { Populus bolleana }\end{array}$ & CRISPR/Cas9 & PdbPDS1 & AT & $\begin{array}{c}\text { mutant shoots at a high frequency and that kanamycin } \\
\text { selection could increase the frequency of homozygous } \\
\text { mutant shoots. }\end{array}$ & [266] \\
\hline $\begin{array}{c}\text { Eucalyptus grandis } \times \\
\text { urophylla }\end{array}$ & CRISPR/Cas9 & $\begin{array}{l}L F Y, \\
F T\end{array}$ & AT & $\begin{array}{l}\text { The absence of male and female gametes and } \\
\text { indeterminacy in floral development due to floral } \\
\text { alteration because of disruption of ELFY function }\end{array}$ & [264] \\
\hline $\begin{array}{l}\text { Populus alba } \times \text { Populus } \\
\text { glandulosa }\end{array}$ & CRISPR/Cas12 & PDS & AT & $\begin{array}{l}\text { AsCas12a system is the most efficient and } \\
\text { optimization of the co-cultivation temperature after } \\
\text { Agrobacterium-mediated transformation from } \\
22 \text { to } 28{ }^{\circ} \mathrm{C} \text { to increase the Cas12a nuclease editing } \\
\text { efficiency in poplar }\end{array}$ & [272] \\
\hline
\end{tabular}

AT = Agrobacterium-mediated transformation

\section{Conclusions}

Due to the long rotation time of a forest plantation and the resulting long generation times necessary to complete a breeding cycle, the use of advanced methods with traditional breeding, such as high-throughput genotyping techniques, have been necessary, allowing the use of more precise approaches for determining the genetic architecture of traits of 
interest, such as genome-wide association studies and genomic selection. Moreover, the introduction of genome editing opens the door to new possibilities and perspectives in theoretical genetics and breeding science of forest trees and the fast remodeling of varieties. In this sense, mutations have greatly enhanced genetic resources for forest trees throughout the globe. With the development of TILLING as a high-throughput mutant screening method, stable gene-specific mutations are now extremely efficient. TILLING screening allows for more accurate detection of mutations at particular loci or genes. On the other hand, the development of new techniques such as CRISPR-based method has the potential to sustain productivity with less effort and cost substantially. More sophisticated techniques must be used to further complicate matters in selecting genome editing reagents and procedures for the regeneration of mutant plants. According to this, we believe that such problems will be adequately handled in the future.

Author Contributions: Conceptualization, S.A. and F.M.-P., Writing-Original draft preparation, S.A., P.B., M.A. and F.M.-P. Writing-Review and editing, P.B. and F.M.-P. supervision. All authors have read and agreed to the published version of the manuscript.

Funding: The Chilean National Fund for Scientific and Technological Development (FONDECYT) grant number 1201973.

Institutional Review Board Statement: Not applicable.

Informed Consent Statement: Not applicable.

Data Availability Statement: Data are contained within the article.

Acknowledgments: Sunny Ahmar thanks to Agencia Nacional de Investigación y Desarrollo de Chile (ANID) Doctorado Nacional/2021-21210254.

Conflicts of Interest: The authors have no conflict of interest.

\section{References}

1. Maldonado, C.; Mora-Poblete, F.; Contreras-Soto, R.I.; Ahmar, S.; Chen, J.-T.; Júnior, A.T.D.A.; Scapim, C.A. Genome-Wide Prediction of Complex Traits in Two Outcrossing Plant Species Through Deep Learning and Bayesian Regularized Neural Network. Front. Plant Sci. 2020, 11, 1734. [CrossRef]

2. Gray, L.K.; Rweyongeza, D.; Hamann, A.; John, S.; Thomas, B.R. Developing management strategies for tree improvement programs under climate change: Insights gained from long-term field trials with lodgepole pine. For. Ecol. Manag. 2016, 377, 128-138. [CrossRef]

3. Mora-Poblete, F.; Ballesta, P.; Lobos, G.A.; Molina-Montenegro, M.; Gleadow, R.; Ahmar, S.; Jiménez-Aspee, F. Genome-wide association study of cyanogenic glycosides, proline, sugars, and pigments in Eucalyptus cladocalyx after 18 consecutive dry summers. Physiol. Plant. 2021. [CrossRef]

4. Ding, C.; Hamann, A.; Yang, R.C.; Brouard, J.S. Genetic parameters of growth and adaptive traits in aspen (Populus tremuloides): Implications for tree breeding in a warming world. PLoS ONE 2020, 15, e229225. [CrossRef] [PubMed]

5. Isaac-Renton, M.; Stoehr, M.; Statland, C.B.; Woods, J. Tree breeding and silviculture: Douglas-fir volume gains with minimal wood quality loss under variable planting densities. For. Ecol. Manag. 2020, 465, 118094. [CrossRef]

6. Cortés, A.J.; Restrepo-Montoya, M.; Bedoya-Canas, L.E. Modern Strategies to Assess and Breed Forest Tree Adaptation to Changing Climate. Front. Plant Sci. 2020, 11, 583323. [CrossRef] [PubMed]

7. Bouvet, J.-M.; Ekomono, C.G.M.; Brendel, O.; Laclau, J.-P.; Bouillet, J.-P.; Epron, D. Selecting for water use efficiency, wood chemical traits and biomass with genomic selection in a Eucalyptus breeding program. For. Ecol. Manag. 2020, 465, 118092. [CrossRef]

8. $\quad$ Alves, R.S.; Rocha, J.R.D.A.S.D.C.; Teodoro, P.E.; De Resende, M.D.V.; Henriques, E.P.; Silva, L.A.; Carneiro, P.C.S.; Bhering, L.L. Multiple-trait BLUP: A suitable strategy for genetic selection of Eucalyptus. Tree Genet. Genomes 2018, 14, 77. [CrossRef]

9. Pastorino, M.J.; Marchelli, P. Low Intensity Breeding of Native Forest Trees in Argentina; Springer: Berlin/Heidelberg, Germany, 2021.

10. Lebedev, V.G.; Lebedeva, T.N.; Chernodubov, A.I.; Shestibratov, K.A. Genomic Selection for Forest Tree Improvement: Methods, Achievements and Perspectives. Forests 2020, 11, 1190. [CrossRef]

11. Crossa, J.; Pérez-Rodríguez, P.; Cuevas, J.; Montesinos-Lopez, O.A.; Jarquín, D.; Campos, G.D.L.; Burgueño, J.; González-Camacho, J.M.; Pérez-Elizalde, S.; Beyene, Y.; et al. Genomic Selection in Plant Breeding: Methods, Models, and Perspectives. Trends Plant Sci. 2017, 22, 961-975. [CrossRef]

12. Beaulieu, J.; Doerksen, T.; Clément, S.; Mackay, J.; Bousquet, J. Accuracy of genomic selection models in a large population of open-pollinated families in white spruce. Heredity 2014, 113, 343-352. [CrossRef] 
13. Ballesta, P.; Serra, N.; Guerra, F.P.; Hasbún, R.; Mora, F. Genomic Prediction of Growth and Stem Quality Traits in Eucalyptus globulus Labill. at Its Southernmost Distribution Limit in Chile. Forests 2018, 9, 779. [CrossRef]

14. Zhang, J.; Song, Q.; Cregan, P.B.; Jiang, G.L. Genome-wide association study, genomic prediction and marker-assisted selec-tion for seed weight in soybean (Glycine max). Theor. Appl. Genet. 2016, 129, 117-130. [CrossRef]

15. Goddard, M.E.; Hayes, B.J.; Meuwissen, T.H.E. Using the genomic relationship matrix to predict the accuracy of genomic selection. J. Anim. Breed. Genet. 2011, 128, 409-421. [CrossRef]

16. Scutari, M.; Mackay, I.; Balding, D. Using Genetic Distance to Infer the Accuracy of Genomic Prediction. PLoS Genet. 2016, 12, e1006288. [CrossRef]

17. Lee, S.H.; Clark, S.; Van Der Werf, J.H.J. Estimation of genomic prediction accuracy from reference populations with vary-ing degrees of relationship. PLoS ONE 2017, 12, e0189775. [CrossRef]

18. Ly, D.; Hamblin, M.; Rabbi, I.Y.; Gedil, M.; Bakare, M.A.; Gauch Jr, H.; Okechukwu, R.U.; Dixon, A.; Kulakow, P.A.; Jan-nink, J.-L. Relatedness and genotype $\mathrm{x}$ environment interaction affect prediction accuracies in genomic selection: A study in cassava. Crop Sci. 2013, 53, 1312-1325. [CrossRef]

19. Thistlethwaite, F.R.; El-Dien, O.G.; Ratcliffe, B.; Klápště, J.; Porth, I.; Chen, C.; Stoehr, M.U.; Ingvarsson, P.K.; El-Kassaby, Y.A. Linkage disequilibrium vs. pedigree: Genomic selection prediction accuracy in conifer species. PLoS ONE 2020, 15, e0232201. [CrossRef] [PubMed]

20. Norman, A.; Taylor, J.; Edwards, J.; Kuchel, H. Optimising Genomic Selection in Wheat: Effect of Marker Density, Population Size and Population Structure on Prediction Accuracy. G3 Genes Genomes Genet. 2018, 8, 2889-2899. [CrossRef] [PubMed]

21. Wientjes, Y.C.J.; Veerkamp, R.F.; Calus, M.P.L. The Effect of Linkage Disequilibrium and Family Relationships on the Reliability of Genomic Prediction. Genetics 2013, 193, 621-631. [CrossRef]

22. Wolc, A.; Zhao, H.H.; Arango, J.; Settar, P.; Fulton, J.E.; O'Sullivan, N.P.; Preisinger, R.; Stricker, C.; Habier, D.; Fernando, R.L.; et al. Response and inbreeding from a genomic selection experiment in layer chickens. Genet. Sel. Evol. 2015, 47, 1-12. [CrossRef]

23. Sun, X.; Fernando, R.; Dekkers, J. Contributions of linkage disequilibrium and co-segregation information to the accuracy of genomic prediction. Genet. Sel. Evol. 2016, 48, 77. [CrossRef]

24. Schopp, P.; Müller, D.; Technow, F.; Melchinger, A.E. Accuracy of Genomic Prediction in Synthetic Populations Depending on the Number of Parents, Relatedness, and Ancestral Linkage Disequilibrium. Genetics 2017, 205, 441-454. [CrossRef]

25. Velazco, J.G.; Malosetti, M.; Hunt, C.H.; Mace, E.S.; Jordan, D.R.; van Eeuwijk, F.A. Combining pedigree and genomic in-formation to improve prediction quality: An example in sorghum. Theor. Appl. Genet. 2019, 132, 2055-2067. [CrossRef]

26. Klápště, J.; Suontama, M.; Telfer, E.; Graham, N.; Low, C.; Stovold, T.; McKinley, R.; Dungey, H. Exploration of genetic ar-chitecture through sib-ship reconstruction in advanced breeding population of Eucalyptus nitens. PLoS ONE 2017, 12, e0185137. [CrossRef]

27. Edwards, D. Two molecular measures of relatedness based on haplotype sharing. BMC Bioinform. 2015, 16, 383. [CrossRef] [PubMed]

28. Howard, N.P.; Van De Weg, E.; Bedford, D.S.; Peace, C.P.; Vanderzande, S.; Clark, M.D.; Teh, S.L.; Cai, L.; Luby, J.J. Eluci-dation of the Honeycrisp' pedigree through haplotype analysis with a multi-family integrated SNP linkage map and a large apple (Malus $\times$ domestica) pedigree-connected SNP data set. Horticult. Res. 2017, 4, 1-7. [CrossRef]

29. Mathew, B.; Léon, J.; Sillanpää, M.J. A novel linkage-disequilibrium corrected genomic relationship matrix for SNP-heritability estimation and genomic prediction. Heredity 2018, 120, 356-368. [CrossRef] [PubMed]

30. Calus, M.P.L.; Meuwissen, T.H.E.; de Roos, A.P.W.; Veerkamp, R.F. Accuracy of Genomic Selection Using Different Methods to Define Haplotypes. Genetics 2008, 178, 553-561. [CrossRef] [PubMed]

31. Matias, F.I.; Galli, G.; Granato, I.S.C.; Fritsche-Neto, R. Genomic Prediction of Autogamous and Allogamous Plants by SNPs and Haplotypes. Crop Sci. 2017, 57, 2951-2958. [CrossRef]

32. He, S.; Thistlethwaite, R.; Forrest, K.; Shi, F.; Hayden, M.; Trethowan, R.; Daetwyler, H.D. Extension of a haplotype-based genomic prediction model to manage multi-environment wheat data using environmental covariates. Theor. Appl. Genet. 2019, 132, 3143-3154. [CrossRef]

33. Sallam, A.H.; Conley, E.; Prakapenka, D.; Da, Y.; Anderson, J.A. Improving prediction accuracy using multi-allelic haplo-type prediction and training population optimization in wheat. G3 Genes Genomes Genet. 2020, 10, 2265-2273.

34. Lan, S.; Zheng, C.; Hauck, K.; McCausland, M.; Duguid, S.D.; Booker, H.M.; Cloutier, S.; You, F.M. Genomic Prediction Accuracy of Seven Breeding Selection Traits Improved by QTL Identification in Flax. Int. J. Mol. Sci. 2020, 21, 1577. [CrossRef] [PubMed]

35. Villumsen, T.M.; Janss, L. Bayesian genomic selection: The effect of haplotype length and priors. BMC Proc. 2009,3 , S11. [CrossRef] [PubMed]

36. Ballesta, P.; Maldonado, C.; Pérez-Rodríguez, P.; Mora, F. SNP and Haplotype-Based Genomic Selection of Quantitative Traits in Eucalyptus globulus. Plants 2019, 8, 331. [CrossRef] [PubMed]

37. Ahmar, S.; Saeed, S.; Khan, M.; Khan, S.U.; Mora-Poblete, F.; Kamran, M.; Faheem, A.; Maqsood, A.; Rauf, M.; Saleem, S.; et al. A Revolution toward Gene-Editing Technology and Its Application to Crop Improvement. Int. J. Mol. Sci. 2020, 21, 5665. [CrossRef] [PubMed]

38. Ahmar, S.; Gill, R.A.; Jung, K.-H.; Faheem, A.; Qasim, M.U.; Mubeen, M.; Zhou, W. Conventional and Molecular Techniques from Simple Breeding to Speed Breeding in Crop Plants: Recent Advances and Future Outlook. Int. J. Mol. Sci. 2020, 21, 2590. [CrossRef] 
39. Ran, Y.; Patron, N.; Kay, P.; Wong, D.; Buchanan, M.; Cao, Y.Y.; Sawbridge, T.; Davies, J.P.; Mason, J.; Webb, S.R.; et al. Zinc finger nuclease-mediated precision genome editing of an endogenous gene in hexaploid bread wheat (Triticum aes-tivum) using a DNA repair template. Plant Biotechnol. J. 2018, 16, 2088-2101. [CrossRef]

40. Luo, M.; Li, H.; Chakraborty, S.; Morbitzer, R.; Rinaldo, A.; Upadhyaya, N.; Bhatt, D.; Louis, S.; Richardson, T.; Lahaye, T.; et al. Efficient TALEN -mediated gene editing in wheat. Plant Biotechnol. J. 2019, 17, 2026-2028. [CrossRef]

41. Li, J.; Zhang, S.; Zhang, R.; Gao, J.; Qi, Y.; Song, G.; Li, W.; Li, Y.; Li, G. Efficient multiplex genome editing by CRISPR/Cas9 in common wheat. Plant Biotechnol. J. 2020, 19, 427-429. [CrossRef]

42. Kieu, N.P.; Lenman, M.; Wang, E.S.; Petersen, B.L.; Andreasson, E. Mutations introduced in susceptibility genes through CRISPR/Cas9 genome editing confer increased late blight resistance in potatoes. Sci. Rep. 2021, 11, 1-12. [CrossRef]

43. Lee, J.E.; Neumann, M.; Duro, D.I.; Schmid, M. CRISPR-based tools for targeted transcriptional and epigenetic regulation in plants. PLoS ONE 2019, 14, e0222778. [CrossRef]

44. Moradpour, M.; Abdulah, S.N.A. CRISPR/dCas9 platforms in plants: Strategies and applications beyond genome editing. Plant Biotechnol. J. 2019, 18, 32-44. [CrossRef]

45. De Almeida Filho, J.E.; Guimarães, J.F.R.; Fonsceca, E.; Silva, F.; De Resende, M.D.V.; Muñoz, P.; Kirst, M.; De Resende, M.F.R. Genomic prediction of additive and non-additive effects using genetic markers and pedigrees. G3 Genes Genomes Genet. 2019, 9 , 2739-2748. [CrossRef]

46. Zapata-Valenzuela, J.; Whetten, R.W.; Neale, D.; McKeand, S.; Isik, F. Genomic Estimated Breeding Values Using Genomic Relationship Matrices in a Cloned Population of Loblolly Pine. G3 Genes Genomes Genet. 2013, 3, 909-916. [CrossRef]

47. Kumar, S.; Molloy, C.; Muñoz, P.; Daetwyler, H.; Chagné, D.; Volz, R. Genome-enabled estimates of additive and nonaddi-tive genetic variances and prediction of apple phenotypes across environments. G3 Genes Genomes Genet. 2015, 5, $2711-2718$.

48. Perron, M.; DeBlois, J.; Desponts, M. Use of resampling to assess optimal subgroup composition for estimating genetic pa-rameters from progeny trials. Tree Genet. Genomes 2013, 9, 129-143. [CrossRef]

49. Tambarussi, E.V.; Pereira, F.B.; Da Silva, P.H.M.; Lee, D.; Bush, D. Are tree breeders properly predicting genetic gain? A case study involving Corymbia species. Euphytica 2018, 214, 150. [CrossRef]

50. $\mathrm{Wu}$, H.X. Benefits and risks of using clones in forestry-A review. Scand. J. For. Res. 2019, 34, 352-359. [CrossRef]

51. Mora, F.; Serra, N. Bayesian estimation of genetic parameters for growth, stem straightness, and survival in Eucalyptus globulus on an Andean Foothill site. Tree Genet. Genomes 2014, 10, 711-719. [CrossRef]

52. Chen, Z.-Q.; Karlsson, B.; Lundqvist, S.-O.; Gil, M.R.G.; Olsson, L.; Wu, H.X. Estimating solid wood properties using Pilodyn and acoustic velocity on standing trees of Norway spruce. Ann. For. Sci. 2015, 72, 499-508. [CrossRef]

53. Wu, S.; Zhu, Y.; Xu, J.; Lu, Z.; Chen, G.; Song, P.; Guo, W. Genetic variation and genetic gain for energy production, growth traits and wood properties in Eucalyptus hybrid clones in China. Aust. For. 2017, 80, 57-65. [CrossRef]

54. Isik, F.; McKeand, S.E. Fourth cycle breeding and testing strategy for Pinus taeda in the NC State University Cooperative Tree Improvement Program. Tree Genet. Genomes 2019, 15, 1-2. [CrossRef]

55. Hiraoka, Y.; Miura, M.; Fukatsu, E.; Iki, T.; Yamanobe, T.; Kurita, M.; Isoda, K.; Kubota, M.; Takahashi, M. Time trends of genetic parameters and genetic gains and optimum selection age for growth traits in sugi (Cryptomeria japonica) based on progeny tests conducted throughout Japan. J. For. Res. 2019, 24, 303-312. [CrossRef]

56. Gamal El-Dien, O.; Ratcliffe, B.; Klápště, J.; Chen, C.; Porth, I.; El-Kassaby, Y.A. Prediction accuracies for growth and wood attributes of interior spruce in space using genotyping-by-sequencing. BMC Genom. 2015, 16, 370. [CrossRef]

57. Klápště, J.; Suontama, M.; Dungey, H.S.; Telfer, E.J.; Graham, N.J.; Low, C.B.; Stovold, G.T. Effect of Hidden Relatedness on Single-Step Genetic Evaluation in an Advanced Open-Pollinated Breeding Program. J. Hered. 2018, 109, 802-810. [CrossRef]

58. Bush, D.; Kain, D.; Kanowski, P.; Matheson, C. Genetic parameter estimates informed by a marker-based pedigree: A case study with Eucalyptus cladocalyx in southern Australia. Tree Genet. Genomes 2014, 11, 798. [CrossRef]

59. Henderson, C.R. Applications of Linear Models in Animal Breeding; Cabi: Wallingford, UK, 1984.

60. Henderson, C.R. Selection index and expected genetic advance. Stat. Genet. Plant Breed. 1963, 141-153.

61. Henderson, C.R. Sire Evaluation and Genetic Trends. J. Anim. Sci. 1973, 1973, 10-41. [CrossRef]

62. White, T.L.; Hodge, G.R. Best linear prediction of breeding values in a forest tree improvement program. Theor. Appl. Genet. 1988, 76, 719-727. [CrossRef] [PubMed]

63. Viana, J.M.S.; Sobreira, F.M.; De Resende, M.D.V.; Faria, V.R. Multi-trait BLUP in half-sib selection of annual crops. Plant Breed. 2010, 129, 599-604. [CrossRef]

64. Zhou, L.; Chen, Z.; Olsson, L.; Grahn, T.; Karlsson, B.; Wu, H.X.; Lundqvist, S.O.; García-Gil, M.R. Effect of number of an-nual rings and tree ages on genomic predictive ability for solid wood properties of Norway spruce. BMC Genom. 2020, $21,323$. [CrossRef]

65. Mphahlele, M.M.; Isik, F.; Mostert-O’Neill, M.M.; Reynolds, S.M.; Hodge, G.R.; Myburg, A.A. Expected benefits of genomic selection for growth and wood quality traits in Eucalyptus grandis. Tree Genet. Genomes 2020, 16, 1-12. [CrossRef]

66. Sverrisdóttir, E.; Byrne, S.; Sundmark, E.H.R.; Johnsen, H.; Kirk, H.G.; Asp, T.; Janss, L.; Nielsen, E.H.R. Genomic prediction of starch content and chipping quality in tetraploid potato using genotyping-by-sequencing. Theor. Appl. Genet. 2017, 130, 2091-2108. [CrossRef]

67. Kumar, S.; Banks, T.W.; Cloutier, S. SNP discovery through next-generation sequencing and its applications. Int. J. Plant Genom. 2012, 2012, 503-511. [CrossRef] 
68. Hayward, A.C.; Tollenaere, R.; Dalton-Morgan, J.; Batley, J. Molecular marker applications in plants. Methods Mol. Biol. 2015, 13-27.

69. Nadeem, M.A.; Nawaz, M.A.; Shahid, M.Q.; Doğan, Y.; Comertpay, G.; Yıldız, M.; Hatipoğlu, R.; Ahmad, F.; Alsaleh, A.; Labhane, N.; et al. DNA molecular markers in plant breeding: Current status and recent advancements in genomic selection and genome editing. Biotechnol. Biotechnol. Equip. 2017, 32, 261-285. [CrossRef]

70. Cobb, J.N.; Biswas, P.S.; Platten, J.D. Back to the future: Revisiting MAS as a tool for modern plant breeding. Theor. Appl. Genet. 2018, 132, 647-667. [CrossRef]

71. Pootakham, W.; Jomchai, N.; Ruang-Areerate, P.; Shearman, J.R.; Sonthirod, C.; Sangsrakru, D.; Tragoonrung, S.; Tangphatsornruang, S. Genome-wide SNP discovery and identification of QTL associated with agronomic traits in oil palm using genotyping-by-sequencing (GBS). Genomics 2015, 105, 288-295. [CrossRef] [PubMed]

72. Brenner, C.; Weir, B. Issues and strategies in the DNA identification of World Trade Center victims. Theor. Popul. Biol. 2003, 63, 173-178. [CrossRef]

73. Seddon, J.M.; Parker, H.G.; Ostrander, E.A.; Ellegren, H. SNPs in ecological and conservation studies: A test in the Scandi-navian wolf population. Mol. Ecol. 2005, 14, 503-511. [CrossRef]

74. Yu, H.; Xie, W.; Wang, J.; Xing, Y.; Xu, C.; Li, X.; Xiao, J.; Zhang, Q. Gains in QTL detection using an ultra-high density SNP map based on population sequencing relative to traditional RFLP/SSR markers. PLoS ONE 2011, 6, e17595.

75. Adhikari, S.; Saha, S.; Biswas, A.; Rana, T.S.; Bandyopadhyay, T.K.; Ghosh, P. Application of molecular markers in plant genome analysis: A review. Nucleus 2017, 60, 283-297. [CrossRef]

76. Garrido-Cardenas, J.A.; Valle, C.M.; Manzano-Agugliaro, F. Trends in plant research using molecular markers. Planta 2017, 247, 543-557. [CrossRef]

77. Harismendy, O.; Ng, P.C.; Strausberg, R.L.; Wang, X.; Stockwell, T.B.; Beeson, K.Y.; Schork, N.J.; Murray, S.S.; Topol, E.J.; Levy, S.; et al. Evaluation of next generation sequencing platforms for population targeted sequencing studies. Genome Biol. 2009, 10, R32. [CrossRef] [PubMed]

78. Paszkiewicz, K.; Studholme, D.J. High-throughput sequencing data analysis software: Current state and future developments. In Bioinformatics for High Throughput Sequencing; Springer: Berlin/Heidelberg, Germany, 2012; pp. 231-248.

79. Kharabian-Masouleh, A.; Waters, D.L.E.; Reinke, R.F.; Henry, R.J. Discovery of polymorphisms in starch-related genes in rice germplasm by amplification of pooled DNA and deeply parallel sequencing. Plant Biotechnol. J. 2011, 9, 1074-1085. [CrossRef]

80. Chandra, S.; Singh, D.; Pathak, J.; Kumari, S.; Kumar, M.; Poddar, R.; Balyan, H.S.; Prabhu, K.V.; Gupta, P.K.; Mukhopadhyay, K. SNP discovery from next-generation transcriptome sequencing data and their validation using KASP assay in wheat (Triticum aestivum L.). Mol. Breed. 2017, 37. [CrossRef]

81. Silva-Junior, O.B.; Faria, D.A.; Grattapaglia, D. A flexible multi-species genome-wide 60K SNP chip developed from pooled resequencing of 240 Eucalyptus tree genomes across 12 species. New Phytol. 2015, 206, 1527-1540. [CrossRef] [PubMed]

82. Ulaszewski, B.; Meger, J.; Burczyk, J. Comparative analysis of SNP discovery and genotyping in Fagus sylvatica L. and Quercus robur L. using RADseq, GBS, and ddRAD methods. Forests 2021, 12, 222. [CrossRef]

83. Livingstone, D.; Royaert, S.; Stack, C.; Mockaitis, K.; May, G.; Farmer, A.; Saski, C.; Schnell, R.; Kuhn, D.; Motamayor, J.C. Making a chocolate chip: Development and evaluation of a 6K SNP array forTheobroma cacao. DNA Res. 2015, 22, 279-291. [CrossRef] [PubMed]

84. Peace, C.; Bassil, N.; Main, R.; Ficklin, S.; Rosyara, U.R.; Stegmeir, T.; Sebolt, A.; Gilmore, B.; Lawley, C.; Mockler, T.C.; et al. Development and Evaluation of a Genome-Wide 6K SNP Array for Diploid Sweet Cherry and Tetraploid Sour Cherry. PLoS ONE 2012, 7, e48305. [CrossRef] [PubMed]

85. Sun, C.; Dong, Z.; Zhao, L.; Ren, Y.; Zhang, N.; Chen, F. The Wheat 660K SNP array demonstrates great potential for markerassisted selection in polyploid wheat. Plant Biotechnol. J. 2020, 18, 1354-1360. [CrossRef]

86. Singh, N.; Jayaswal, P.K.; Panda, K.; Mandal, P.; Kumar, V.; Singh, B.; Mishra, S.; Singh, Y.; Singh, R.; Rai, V.; et al. Sin-gle-copy gene based $50 \mathrm{~K}$ SNP chip for genetic studies and molecular breeding in rice. Sci. Rep. 2015, 5, 1-9.

87. Geraldes, A.; Difazio, S.P.; Slavov, G.T.; Ranjan, P.; Muchero, W.; Hannemann, J.; Gunter, L.E.; Wymore, A.M.; Grassa, C.J.; Farzaneh, N.; et al. A 34K SNP genotyping array for Populus trichocarpa: Design, application to the study of natural popula-tions and transferability to other Populus species. Mol. Ecol. Res. 2013, 13, 306-323. [CrossRef]

88. Pavy, N.; Gagnon, F.; Rigault, P.; Blais, S.; Deschênes, A.; Boyle, B.; Pelgas, B.; Deslauriers, M.; Clément, S.; Lavigne, P.; et al. Development of high-density SNP genotyping arrays for white spruce (Picea glauca) and transferability to subtropical and nordic congeners. Mol. Ecol. Res. 2013, 13, 324-336. [CrossRef]

89. Lepoittevin, C.; Bodénès, C.; Chancerel, E.; Villate, L.; Lang, T.; Lesur, I.; Boury, C.; Ehrenmann, F.; Zelenika, D.; Boland, A.; et al. Single-nucleotide polymorphism discovery and validation in high-density SNP array for genetic analysis in European white oaks. Mol. Ecol. Res. 2015, 15, 1446-1459. [CrossRef] [PubMed]

90. Silva, P.I.T.; Silva-Junior, O.B.; Resende, L.V.; Sousa, V.A.; Aguiar, A.V.; Grattapaglia, D. A 3K Axiom SNP array from a transcriptome-wide SNP resource sheds new light on the genetic diversity and structure of the iconic subtropical conifer tree Araucaria angustifolia (Bert.) Kuntze. PLoS ONE 2020, 15, e0230404. [CrossRef]

91. Perry, A.; Wachowiak, W.; Downing, A.; Talbot, R.; Cavers, S. Development of a single nucleotide polymorphism array for population genomic studies in four European pine species. Mol. Ecol. Resour. 2020, 20, 1697-1705. [CrossRef] 
92. Howe, G.T.; Jayawickrama, K.; Kolpak, S.E.; Kling, J.; Trappe, M.; Hipkins, V.; Ye, T.; Guida, S.; Cronn, R.; Cushman, S.A.; et al. An Axiom SNP genotyping array for Douglas-fir. BMC Genom. 2020, 21, 9. [CrossRef]

93. Bernhardsson, C.; Zan, Y.; Chen, Z.; Ingvarsson, P.K.; Wu, H.X. Development of a highly efficient 50K single nucleotide polymorphism genotyping array for the large and complex genome of Norway spruce (Picea abies L. Karst) by whole ge-nome resequencing and its transferability to other spruce species. Mol. Ecol. Res. 2021, 21, 880-896. [CrossRef]

94. Pellicer, J.; Hidalgo, O.; Dodsworth, S.; Leitch, I.J. Genome Size Diversity and Its Impact on the Evolution of Land Plants. Genes 2018, 9, 88. [CrossRef] [PubMed]

95. Faivre-Rampant, P.; Zaina, G.; Jorge, V.; Giacomello, S.; Segura, V.; Scalabrin, S.; Guérin, V.; De Paoli, E.; Aluome, C.; Viger, M.; et al. New resources for genetic studies in Populus nigra: Genome-wide SNP discovery and development of a 12k Infin-ium array. Mol. Ecol. Resour. 2016, 16, 1023-1036. [CrossRef] [PubMed]

96. Telfer, E.; Graham, N.; Macdonald, L.; Li, Y.; Klápště, J.; Jr, M.R.; Neves, L.G.; Dungey, H.; Wilcox, P. A high-density exome capture genotype-by-sequencing panel for forestry breeding in Pinus radiata. PLoS ONE 2019, 14, e0222640. [CrossRef]

97. Ramos, A.; Usié, A.; Barbosa, P.; Barros, P.M.; Capote, T.; Chaves, I.; Simões, F.; Abreu, I.; Carrasquinho, I.; Faro, C.; et al. The draft genome sequence of cork oak. Sci. Data 2018, 5, 180069. [CrossRef]

98. Zoldoš, V.; Papeš, D.; Brown, S.C.; Panaud, O.; Šiljak-Yakovlev, S. Genome size and base composition of seven Quercus species: Inter- and intra-population variation. Genome 1998, 41, 162-168. [CrossRef]

99. Tuskan, G.; DiFazio, S.; Jansson, S.; Bohlmann, J.; Grigoriev, I.; Hellsten, U.; Putnam, N.; Ralph, S.; Rombauts, S.; Salamov, A.; et al. The Genome of Black Cottonwood, Populus trichocarpa (Torr. \& Gray). Science 2006, 313, 1596-1604. [CrossRef]

100. Kovach, A.; Wegrzyn, J.L.; Parra, G.; Holt, C.; Bruening, G.E.; Loopstra, C.A.; Hartigan, J.; Yandell, M.; Langley, C.H.; Korf, I.; et al. The Pinus taeda genome is characterized by diverse and highly diverged repetitive sequences. BMC Genom. 2010, 11, 420. [CrossRef]

101. Zimin, A.; Stevens, K.A.; Crepeau, M.; Holtz-Morris, A.; Koriabine, M.; Marçais, G.; Puiu, D.; Roberts, M.; Wegrzyn, J.; de Jong, P.J.; et al. Sequencing and Assembly of the 22-Gb Loblolly Pine Genome. Genetics 2014, 196, 875-890. [CrossRef]

102. Zimin, A.V.; Stevens, K.A.; Crepeau, M.; Puiu, D.; Wegrzyn, J.; Yorke, J.A.; Langley, C.H.; Neale, D.B.; Salzberg, S.L. An improved assembly of the loblolly pine mega-genome using long-read single-molecule sequencing. GigaScience 2017, 6, 1-4. [CrossRef]

103. De La Torre, A.R.; Puiu, D.; Crepeau, M.W.; Stevens, K.; Salzberg, S.L.; Langley, C.H.; Neale, D.B. Genomic architecture of complex traits in loblolly pine. New Phytol. 2018, 221, 1789-1801. [CrossRef]

104. Myburg, A.A.; Grattapaglia, D.; Tuskan, G.; Hellsten, U.; Hayes, R.; Grimwood, J.; Jenkins, J.; Lindquist, E.; Tice, H.; Bauer, D.; et al. The genome of Eucalyptus grandis. Nature 2014, 510, 356-362. [CrossRef] [PubMed]

105. Meuwissen, E.T.H.; Hayes, B.; Goddard, M. Prediction of Total Genetic Value Using Genome-Wide Dense Marker Maps. Genetics 2001, 157, 1819-1829. [CrossRef]

106. Crossa, J.; De Los Campos, G.; Pérez, P.; Gianola, D.; Burgueño, J.; Araus, J.L.; Makumbi, D.; Singh, R.P.; Dreisigacker, S.; Yan, J.; et al. Prediction of genetic values of quantitative traits in plant breeding using pedigree and molecular markers. Genetics 2010, 186, 713-724. [CrossRef] [PubMed]

107. Liu, G.; Zhao, Y.; Gowda, M.; Longin, C.F.H.; Reif, J.C.; Mette, M.F. Predicting Hybrid Performances for Quality Traits through Genomic-Assisted Approaches in Central European Wheat. PLoS ONE 2016, 11, e0158635. [CrossRef] [PubMed]

108. Du, Q.; Gong, C.; Wang, Q.; Zhou, D.; Yang, H.; Pan, W.; Li, B.; Zhang, D. Genetic architecture of growth traits in Populus revealed by integrated quantitative trait locus (QTL) analysis and association studies. New Phytol. 2015, 209, 1067-1082. [CrossRef] [PubMed]

109. Bartholomé, J.; Bink, M.C.; Van Heerwaarden, J.; Chancerel, E.; Boury, C.; Lesur, I.; Isik, F.; Bouffier, L.; Plomion, C. Linkage and Association Mapping for Two Major Traits Used in the Maritime Pine Breeding Program: Height Growth and Stem Straightness. PLoS ONE 2016, 11, e0165323. [CrossRef] [PubMed]

110. Mori, H.; Ueno, S.; Ujino-Ihara, T.; Fujiwara, T.; Yamashita, K.; Kanetani, S.; Endo, R.; Matsumoto, A.; Uchiyama, K.; Matsui, Y.; et al. Mapping quantitative trait loci for growth and wood property traits in Cryptomeria japonica across multiple environments. Tree Genet. Genomes 2019, 15, 43. [CrossRef]

111. Valenzuela, C.E.; Ballesta, P.; Ahmar, S.; Fiaz, S.; Heidari, P.; Maldonado, C.; Mora-Poblete, F. Haplotype- and SNP-Based GWAS for Growth and Wood Quality Traits in Eucalyptus cladocalyx Trees under Arid Conditions. Plants 2021, 10, 148. [CrossRef]

112. Missiaggia, A.A.; Piacezzi, A.L.; Grattapaglia, D. Genetic mapping of Eef1, a major effect QTL for early flowering in Eucalyptus grandis. Tree Genet. Genomes 2005, 1, 79-84. [CrossRef]

113. Bundock, P.C.; Potts, B.M.; Vaillancourt, R.E. Detection and stability of quantitative trait loci (QTL) in Eucalyptus globulus. Tree Genet. Genomes 2007, 4, 85-95. [CrossRef]

114. Arriagada, O.; Júnior, A.T.D.A.; Mora, F. Thirteen years under arid conditions: Exploring marker-trait associations in Eucalyptus cladocalyx for complex traits related to flowering, stem form and growth. Breed. Sci. 2018, 68, 367-374. [CrossRef]

115. Thumma, B.R.; Baltunis, B.S.; Bell, J.C.; Emebiri, L.C.; Moran, G.F.; Southerton, S.G. Quantitative trait locus (QTL) analysis of growth and vegetative propagation traits in Eucalyptus nitens full-sib families. Tree Genet. Genomes 2010, 6, 877-889. [CrossRef]

116. Thavamanikumar, S.; McManus, L.J.; Ades, P.K.; Bossinger, G.; Stackpole, D.J.; Kerr, R.; Hadjigol, S.; Freeman, J.; Vaillancourt, R.; $\mathrm{Zhu}$, P.; et al. Association mapping for wood quality and growth traits in Eucalyptus globulus ssp. globulus Labill identifies nine stable marker-trait associations for seven traits. Tree Genet. Genomes 2014, 10, 1661-1678. [CrossRef] 
117. Resende, R.T.; Resende, M.D.V.; Silva, F.F.; Azevedo, C.F.; Takahashi, E.K.; Silva-Junior, O.B.; Grattapaglia, D. Regional heritability mapping and genome-wide association identify loci for complex growth, wood and disease resistance traits in Eucalyptus. New Phytol. 2017, 213, 1287-1300. [CrossRef]

118. Fahrenkrog, A.M.; Neves, L.G.; Resende, M.F.R.; Vazquez, A.I.; Campos, G.; Dervinis, C.; Sykes, R.; Davis, M.; Davenport, R.; Barbazuk, W.; et al. Genome-wide association study reveals putative regulators of bioenergy traits in Populus deltoides. New Phytol. 2016, 213, 799-811. [CrossRef]

119. Baison, J.; Vidalis, A.; Zhou, L.; Chen, Z.Q.; Li, Z.; Sillanpää, M.J.; Bernhardsson, C.; Scoffield, D.; Forsberg, N.; Olsson, L.; et al. Association mapping identified novel candidate loci affecting wood formation in Norway spruce. bioRxiv 2018, 100, 83-100.

120. Guerra, F.P.; Suren, H.; Holliday, J.; Richards, J.H.; Fiehn, O.; Famula, R.; Stanton, B.J.; Shuren, R.; Sykes, R.; Davis, M.F.; et al. Exome resequencing and GWAS for growth, ecophysiology, and chemical and metabolomic composition of wood of Populus trichocarpa. BMC Genom. 2019, 20, 875. [CrossRef]

121. Valenzuela, C.E.; Ballesta, P.; Maldonado, C.; Baettig, R.; Arriagada, O.; Mafra, G.S.; Mora, F. Bayesian Mapping Reveals Large-Effect Pleiotropic QTLs for Wood Density and Slenderness Index in 17-Year-Old Trees of Eucalyptus cladocalyx. Forests 2019, 10, 241. [CrossRef]

122. Daetwyler, H.D.; Calus, M.P.L.; Pong-Wong, R.; Campos, G.D.L.; Hickey, J.M. Genomic Prediction in Animals and Plants: Simulation of Data, Validation, Reporting, and Benchmarking. Genetics 2013, 193, 347-365. [CrossRef] [PubMed]

123. Supple, M.A.; Bragg, J.G.; Broadhurst, L.M.; Nicotra, A.B.; Byrne, M.; Andrew, R.L.; Widdup, A.; Aitken, N.C.; Borevitz, J.O. Landscape genomic prediction for restoration of a Eucalyptus foundation species under climate change. eLife 2018, 24 , e31835. [CrossRef] [PubMed]

124. Arenas, S.; Cortés, A.J.; Mastretta-Yanes, A.; Jaramillo-Correa, J.P. Evaluating the accuracy of genomic prediction for the management and conservation of relictual natural tree populations. Tree Genet. Genomes 2021, 17, 1-19. [CrossRef]

125. Tibshirani, R. Regression shrinkage and selection via the Lasso. J. R. Stat. Soc. Ser. B (Methodol.) 1996, 58, 267-288. [CrossRef]

126. Habier, D.; Fernando, R.L.; Kizilkaya, K.; Garrick, D.J. Extension of the Bayesian alphabet for genomic selection. BMC Bioinform. 2011, 12, 186. [CrossRef]

127. VanRaden, P.M. Efficient Methods to Compute Genomic Predictions. J. Dairy Sci. 2008, 91, 4414-4423. [CrossRef]

128. Resende, M.F.R.; Muñoz, P.; Garrick, D.; Fernando, R.L.; Davis, J.M.; Jokela, E.J.; Martin, T.; Peter, G.F.; Kirst, M. Accuracy of Genomic Selection Methods in a Standard Data Set of Loblolly Pine (Pinus taeda L.). Genetics 2012, 190, 1503-1510. [CrossRef]

129. Wang, X.; Xu, Y.; Hu, Z.; Xu, C. Genomic selection methods for crop improvement: Current status and prospects. Crop J. 2018, 6, 330-340. [CrossRef]

130. Heslot, N.; Yang, H.P.; Sorrells, M.E.; Jannink, J.L. Genomic selection in plant breeding: A comparison of models. Crop Sci. 2012, 52, 146-160. [CrossRef]

131. Campos, G.D.L.; Hickey, J.M.; Pong-Wong, R.; Daetwyler, H.D.; Calus, M.P.L. Whole-Genome Regression and Prediction Methods Applied to Plant and Animal Breeding. Genetics 2013, 193, 327-345. [CrossRef]

132. Gianola, D.; Fernando, R.L.; Stella, A. Genomic-Assisted Prediction of Genetic Value with Semiparametric Procedures. Genetics 2006, 173, 1761-1776. [CrossRef]

133. Pérez, P.; Campos, G.D.L. Genome-Wide Regression and Prediction with the BGLR Statistical Package. Genetics 2014, $198,483-495$. [CrossRef]

134. Du, C.; Wei, J.; Wang, S.; Jia, Z. Genomic selection using principal component regression. Heredity 2018, 121, 12-23. [CrossRef] [PubMed]

135. Gao, H.; Su, G.; Janss, L.; Zhang, Y.; Lund, M. Model comparison on genomic predictions using high-density markers for different groups of bulls in the Nordic Holstein population. J. Dairy Sci. 2013, 96, 4678-4687. [CrossRef] [PubMed]

136. Wu, X.; Lund, M.; Sun, D.; Zhang, Q.; Su, G. Impact of relationships between test and training animals and among training animals on reliability of genomic prediction. J. Anim. Breed. Genet. 2015, 132, 366-375. [CrossRef] [PubMed]

137. Pook, T.; Freudenthal, J.; Korte, A.; Simianer, H. Using Local Convolutional Neural Networks for Genomic Prediction. Front. Genet. 2020, 11, 1366. [CrossRef]

138. Yin, B.; Balvert, M.A.; Van Der Spek, A.R.; Dutilh, E.B.; Bohté, S.; Veldink, J.; Schönhuth, A. Using the structure of genome data in the design of deep neural networks for predicting amyotrophic lateral sclerosis from genotype. Bioinformatics 2019, 35, i538-i547. [CrossRef]

139. Glória, L.S.; Cruz, C.D.; Vieira, R.A.M.; de Resende, M.D.V.; Lopes, P.S.; de Siqueira, O.H.G.B.D.; Fonseca e Silva, F. Accessing marker effects and heritability estimates from genome prediction by Bayesian regularized neural networks. Livest. Sci. 2016, 191, 91-96. [CrossRef]

140. Leung, M.K.K.; Delong, A.; Alipanahi, B.; Frey, B.J. Machine Learning in Genomic Medicine: A Review of Computational Problems and Data Sets. Proc. IEEE 2015, 104, 176-197. [CrossRef]

141. Gianola, D. Priors in whole-genome regression: The Bayesian alphabet returns. Genetics 2013, 194, 573-596. [CrossRef]

142. Pérez-Rodríguez, P.; Gianola, D.; González-Camacho, J.M.; Crossa, J.; Manès, Y.; Dreisigacker, S. Comparison Between Linear and Non-parametric Regression Models for Genome-Enabled Prediction in Wheat. G3 Genes Genomes Genet. 2012, 2, $1595-1605$. [CrossRef]

143. Zingaretti, L.M.; Gezan, S.A.; Ferrão, L.F.V.; Osorio, L.F.; Monfort, A.; Muñoz, P.R.; Whitaker, V.M.; Pérez-Enciso, M. Exploring Deep Learning for Complex Trait Genomic Prediction in Polyploid Outcrossing Species. Front. Plant Sci. 2020, 11, 25. [CrossRef] 
144. Alves, A.A.C.; Da Costa, R.M.; Bresolin, T.; Júnior, G.A.F.; Espigolan, R.; Ribeiro, A.M.F.; Carvalheiro, R.; De Albuquerque, L.G. Genome-wide prediction for complex traits under the presence of dominance effects in simulated populations using GBLUP and machine learning methods. J. Anim. Sci. 2020, 98, skaa179. [CrossRef]

145. Resende, M.D.V.; Resende, M.F.R.; Sansaloni, C.P.; Petroli, C.D.; Missiaggia, A.A.; Aguiar, A.M.; Abad, J.M.; Takahashi, E.K.; Rosado, A.M.; Faria, D.A.; et al. Genomic selection for growth and wood quality in Eucalyptus: Capturing the missing heritability and accelerating breeding for complex traits in forest trees. New Phytol. 2012, 194, 116-128. [CrossRef]

146. Weber, K.L.; Thallman, R.M.; Keele, J.W.; Snelling, W.M.; Bennett, G.L.; Smith, T.P.L.; McDaneld, T.G.; Allan, M.F.; Van Eenennaam, A.L.; Kuehn, L.A. Accuracy of genomic breeding values in multibreed beef cattle populations derived from deregressed breeding values and phenotypes1,2. J. Anim. Sci. 2012, 90, 4177-4190. [CrossRef] [PubMed]

147. Pryce, J.; Johnston, J.; Hayes, B.; Sahana, G.; Weigel, K.; McParland, S.; Spurlock, D.; Krattenmacher, N.; Spelman, R.; Wall, E.; et al. Imputation of genotypes from low density (50,000 markers) to high density (700,000 markers) of cows from research herds in Europe, North America, and Australasia using 2 reference populations. J. Dairy Sci. 2014, 97, 1799-1811. [CrossRef] [PubMed]

148. Isik, F.; Bartholomé, J.; Farjat, A.; Chancerel, E.; Raffin, A.; Sanchez, L.; Plomion, C.; Bouffier, L. Genomic selection in maritime pine. Plant Sci. 2016, 242, 108-119. [CrossRef] [PubMed]

149. Cappa, E.P.; de Lima, B.M.; da Silva-Junior, O.B.; Garcia, C.C.; Mansfield, S.D.; Grattapaglia, D. Improving genomic prediction of growth and wood traits in Eucalyptus using phenotypes from non-genotyped trees by single-step GBLUP. Plant Sci. 2019, 284, 9-15. [CrossRef]

150. Ballesta, P.; Bush, D.; Silva, F.F.; Mora, F. Genomic Predictions Using Low-Density SNP Markers, Pedigree and GWAS Information: A Case Study with the Non-Model Species Eucalyptus cladocalyx. Plants 2020, 9, 99. [CrossRef] [PubMed]

151. Müller, B.S.F.; Neves, L.G.; Filho, J.E.D.A.; Resende, M.F.R.; Muñoz, P.R.; Dos Santos, P.E.T.; Filho, E.P.; Kirst, M.; Grattapaglia, D. Genomic prediction in contrast to a genome-wide association study in explaining heritable variation of complex growth traits in breeding populations of Eucalyptus. BMC Genom. 2017, 18, 524. [CrossRef]

152. Suontama, M.; Klápště, J.; Telfer, E.; Graham, N.; Stovold, T.; Low, C.; McKinley, R.; Dungey, H. Efficiency of genomic prediction across two Eucalyptus nitens seed orchards with different selection histories. Heredity 2019, 122, 370-379. [CrossRef]

153. Thavamanikumar, S.; Arnold, R.J.; Luo, J.; Thumma, B.R. Genomic Studies Reveal Substantial Dominant Effects and Improved Genomic Predictions in an Open-Pollinated Breeding Population of Eucalyptus pellita. G3 Genes Genomes Genet. 2020, 10, 3751-3763. [CrossRef]

154. Rambolarimanana, T.; Ramamonjisoa, L.; Verhaegen, D.; Tsy, J.-M.L.P.; Jacquin, L.; Cao-Hamadou, T.-V.; Makouanzi, G.; Bouvet, J.-M. Performance of multi-trait genomic selection for Eucalyptus robusta breeding program. Tree Genet. Genomes 2018, 14, 71. [CrossRef]

155. Klápště, J.; Dungey, H.S.; Telfer, E.J.; Suontama, M.; Graham, N.J.; Li, Y.; McKinley, R. Marker Selection in Multivariate Genomic Prediction Improves Accuracy of Low Heritability Traits. Front. Genet. 2020, 11, 499094. [CrossRef]

156. Tan, B.; Grattapaglia, D.; Martins, G.; Ferreira, K.Z.; Sundberg, B.; Ingvarsson, P.K. Evaluating the accuracy of genomic prediction of growth and wood traits in two Eucalyptus species and their F1 hybrids. BMC Plant Biol. 2017, 17, 110. [CrossRef]

157. Cappa, E.P.; El-Kassaby, Y.A.; Muñoz, F.; Garcia, M.N.; Villalba, P.V.; Klápště, J.; Poltri, S.N.M. Genomic-based multiple-trait evaluation in Eucalyptus grandis using dominant DArT markers. Plant Sci. 2018, 271, 27-33. [CrossRef]

158. Durán, R.; Isik, F.; Zapata-Valenzuela, J.; Balocchi, C.; Valenzuela, S. Genomic predictions of breeding values in a cloned Eucalyptus globulus population in Chile. Tree Genet. Genomes 2017, 13, 74. [CrossRef]

159. Jurcic, E.J.; Villalba, P.V.; Pathauer, P.S.; Palazzini, D.A.; Oberschelp, G.P.J.; Harrand, L.; Garcia, M.N.; Aguirre, N.C.; Acuña, C.V.; Martínez, M.C.; et al. Single-step genomic prediction of Eucalyptus dunnii using different identity-by-descent and identity-by-state relationship matrices. Heredity 2021, 18, 1-4.

160. Lenz, P.R.N.; Nadeau, S.; Azaiez, A.; Gérardi, S.; DesLauriers, M.; Perron, M.; Isabel, N.; Beaulieu, J.; Bousquet, J. Genomic prediction for hastening and improving efficiency of forward selection in conifer polycross mating designs: An example from white spruce. Heredity 2020, 124, 562-578. [CrossRef] [PubMed]

161. Beaulieu, J.; Nadeau, S.; Ding, C.; Celedon, J.M.; Azaiez, A.; Ritland, C.; Laverdière, J.P.; Deslauriers, M.; Adams, G.; Fullarton, M.; et al. Genomic selection for resistance to spruce budworm in white spruce and relationships with growth and wood quality traits. Evolut. Appl. 2020, 13, 2704-2722. [CrossRef] [PubMed]

162. Lenz, P.R.; Beaulieu, J.; Mansfield, S.D.; Clément, S.; Desponts, M.; Bousquet, J. Factors affecting the accuracy of genomic selection for growth and wood quality traits in an advanced-breeding population of black spruce (Picea mariana). BMC Genom. 2017, 18, 335. [CrossRef]

163. Ratcliffe, B.; El-Dien, O.G.; Cappa, E.P.; Porth, I.; Klápště, J.; Chen, C.; El-Kassaby, Y.A. Single-Step BLUP with Varying Genotyping Effort in Open-Pollinated Picea glauca. G3 Genes Genomes Genet. 2017, 7, 935-942. [CrossRef]

164. Lenz, P.R.N.; Nadeau, S.; Mottet, M.J.; Perron, M.; Isabel, N.; Beaulieu, J.; Bousquet, J. Multi-trait genomic selection for weevil resistance, growth, and wood quality in Norway spruce. Evolut. Appl. 2020, 13, 76-94. [CrossRef]

165. Chen, Z.-Q.; Baison, J.; Pan, J.; Karlsson, B.; Andersson, B.; Westin, J.; García-Gil, M.R.; Wu, H.X. Accuracy of genomic selection for growth and wood quality traits in two control-pollinated progeny trials using exome capture as the genotyping platform in Norway spruce. BMC Genom. 2018, 19, 946. [CrossRef]

166. Ukrainetz, N.K.; Mansfield, S.D. Assessing the sensitivities of genomic selection for growth and wood quality traits in lodgepole pine using Bayesian models. Tree Genet. Genomes 2019, 16, 14. [CrossRef] 
167. Li, Y.; Klápště, J.; Telfer, E.; Wilcox, P.; Graham, N.; Macdonald, L.; Dungey, H.S. Genomic selection for non-key traits in radiata pine when the documented pedigree is corrected using DNA marker information. BMC Genom. 2019, 20, 1026. [CrossRef] [PubMed]

168. Calleja-Rodriguez, A.; Pan, J.; Funda, T.; Chen, Z.; Baison, J.; Isik, F.; Abrahamsson, S.; Wu, H.X. Evaluation of the efficiency of genomic versus pedigree predictions for growth and wood quality traits in Scots pine. BMC Genom. 2020, 21, 796. [CrossRef] [PubMed]

169. Cros, D.; Mbo-Nkoulou, L.; Bell, J.M.; Oum, J.; Masson, A.; Soumahoro, M.; Tran, D.M.; Achour, Z.; Le Guen, V.; ClementDemange, A. Within-family genomic selection in rubber tree (Hevea brasiliensis) increases genetic gain for rubber production. Ind. Crop. Prod. 2019, 138, 111464. [CrossRef]

170. Souza, L.M.; Francisco, F.R.; Gonçalves, P.S.; Junior, E.J.S.; Le Guen, V.; Fritsche-Neto, R.; Souza, A.P. Genomic Selection in Rubber Tree Breeding: A Comparison of Models and Methods for Managing G $\times$ E Interactions. Front. Plant Sci. 2019, 10, 1353. [CrossRef] [PubMed]

171. Rincent, R.; Charpentier, J.-P.; Faivre-Rampant, P.; Paux, E.; Le Gouis, J.; Bastien, C.; Segura, V. Phenomic Selection Is a Low-Cost and High-Throughput Method Based on Indirect Predictions: Proof of Concept on Wheat and Poplar. G3 Genes Genomes Genet. 2018, 8, 3961-3972. [CrossRef] [PubMed]

172. Thistlethwaite, F.R.; Ratcliffe, B.; Klápště, J.; Porth, I.; Chen, C.; Stoehr, M.U.; El-Kassaby, Y.A. Genomic prediction accuracies in space and time for height and wood density of Douglas-fir using exome capture as the genotyping platform. BMC Genom. 2017, 18, 930. [CrossRef]

173. Brown, M.D.; Glazner, C.G.; Zheng, C.; Thompson, A.E. Inferring Coancestry in Population Samples in the Presence of Linkage Disequilibrium. Genetics 2012, 190, 1447-1460. [CrossRef]

174. Slavov, G.T.; DiFazio, S.P.; Martin, J.; Schackwitz, W.; Muchero, W.; Rodgers-Melnick, E.; Lipphardt, M.F.; Pennacchio, C.P.; Hellsten, U.; Pennacchio, L.A.; et al. Genome resequencing reveals multiscale geographic structure and extensive linkage disequilibrium in the forest tree Populus trichocarpa. New Phytol. 2012, 196, 713-725. [CrossRef]

175. Lu, M.; Krutovsky, K.V.; Nelson, C.D.; Koralewski, T.E.; Byram, T.D.; Loopstra, C.A. Exome genotyping, linkage disequilibrium and population structure in loblolly pine (Pinus taeda L.). BMC Genom. 2016, 17, 730. [CrossRef]

176. Gupta, P.K.; Rustgi, S.; Kulwal, P.L. Linkage disequilibrium and association studies in higher plants: Present status and future prospects. Plant Mol. Biol. 2005, 57, 461-485. [CrossRef]

177. Neale, D.B.; Kremer, A. Forest tree genomics: Growing resources and applications. Nat. Rev. Genet. 2011, 12, 111-122. [CrossRef]

178. Thavamanikumar, S.; Southerton, S.G.; Bossinger, G.; Thumma, B.R. Dissection of complex traits in forest trees-opportunities for marker-assisted selection. Tree Genet. Genomes 2013, 9, 627-639. [CrossRef]

179. Olson, M.S.; Robertson, A.L.; Takebayashi, N.; Silim, S.; Schroeder, W.R.; Tiffin, P. Nucleotide diversity and linkage disequilibrium in balsam poplar (Populus balsamifera). New Phytol. 2010, 186, 526-536. [CrossRef] [PubMed]

180. Kelleher, C.T.; Wilkin, J.; Zhuang, J.; Cortés, A.J.; Perez-Quintero, A.L.; Gallagher, T.F.; Bohlmann, J.; Douglas, C.J.; Ellis, B.E.; Ritland, K. SNP discovery, gene diversity, and linkage disequilibrium in wild populations of Populus tremuloides. Tree Genet. Genomes 2012, 8, 821-829. [CrossRef]

181. Guerra, F.P.; Wegrzyn, J.L.; Sykes, R.; Davis, M.F.; Stanton, B.J.; Neale, D.B. Association genetics of chemical wood properties in black poplar (Populus nigra). New Phytol. 2012, 197, 162-176. [CrossRef] [PubMed]

182. Larsson, H.; Källman, T.; Gyllenstrand, N.; Lascoux, M. Distribution of Long-Range Linkage Disequilibrium and Tajima's D Values in Scandinavian Populations of Norway Spruce (Picea abies). G3 Genes Genomes Genet. 2013, 3, 795-806. [CrossRef]

183. Müller, D.; Schopp, P.; Melchinger, A.E. Selection on Expected Maximum Haploid Breeding Values Can Increase Genetic Gain in Recurrent Genomic Selection. G3 Genes Genomes Genet. 2018, 8, 1173-1181. [CrossRef]

184. Thavamanikumar, S.; McManus, L.J.; Tibbits, J.F.; Bossinger, G. The significance of single nucleotide polymorphisms (SNPs) in Eucalyptus globulus breeding programs. Aust. For. 2011, 74, 23-29. [CrossRef]

185. Stejskal, J.; Lstibůrek, M.; Klápště, J.; Čepl, J.; El-Kassaby, Y.A. Effect of genomic prediction on response to selection in forest tree breeding. Tree Genet. Genomes 2018, 14, 74. [CrossRef]

186. Grattapaglia, D.; Resende, M.D.V. Genomic selection in forest tree breeding. Tree Genet. Genomes 2010, 7, 241-255. [CrossRef]

187. Lorenz, A.J.; Smith, K.P. Adding Genetically Distant Individuals to Training Populations Reduces Genomic Prediction Accuracy in Barley. Crop Sci. 2015, 55, 2657-2667. [CrossRef]

188. Lorenz, A.J.; Smith, K.; Jannink, J. Potential and Optimization of Genomic Selection for Fusarium Head Blight Resistance in Six-Row Barley. Crop Sci. 2012, 52, 1609-1621. [CrossRef]

189. Thorwarth, P.; Ahlemeyer, J.; Bochard, A.-M.; Krumnacker, K.; Blümel, H.; Laubach, E.; Knöchel, N.; Cselényi, L.; Ordon, F.; Schmid, K.J. Genomic prediction ability for yield-related traits in German winter barley elite material. Theor. Appl. Genet. 2017, 130, 1669-1683. [CrossRef] [PubMed]

190. Sapkota, S.; Boyles, R.; Cooper, E.; Brenton, Z.; Myers, M.; Kresovich, S. Impact of sorghum racial structure and diversity on genomic prediction of grain yield components. Crop Sci. 2020, 60, 132-148. [CrossRef]

191. Gienapp, P.; Fior, S.; Guillaume, F.; Lasky, J.R.; Sork, V.L.; Csilléry, K. Genomic Quantitative Genetics to Study Evolution in the Wild. Trends Ecol. Evol. 2017, 32, 897-908. [CrossRef] 
192. Yu, J.; Pressoir, G.; Briggs, W.H.; Bi, I.V.; Yamasaki, M.; Doebley, J.F.; McMullen, M.D.; Gaut, B.S.; Nielsen, D.M.; Holland, J.; et al. A unified mixed-model method for association mapping that accounts for multiple levels of relatedness. Nat. Genet. 2005, 38, 203-208. [CrossRef]

193. Yamamoto, T.; Nagasaki, H.; Yonemaru, J.-I.; Ebana, K.; Nakajima, M.; Shibaya, T.; Yano, M. Fine definition of the pedigree haplotypes of closely related rice cultivars by means of genome-wide discovery of single-nucleotide polymorphisms. $B M C$ Genom. 2010, 11, 267. [CrossRef]

194. Voorrips, R.E.; Bink, M.C.A.M.; Kruisselbrink, J.W.; Putten, H.J.J.K.-V.; Van De Weg, W.E. PediHaplotyper: Software for consistent assignment of marker haplotypes in pedigrees. Mol. Breed. 2016, 36, 1-10. [CrossRef]

195. Pikunova, A.; Madduri, M.; Sedov, E.; Noordijk, Y.; Peil, A.; Troggio, M.; Bus, V.; Visser, R.G.; van de Weg, E. 'Schmidt's Antonovka' is identical to 'Common Antonovka', an apple cultivar widely used in Russia in breeding for biotic and abiotic stresses. Tree Genet. Genomes 2013, 10, 261-271. [CrossRef]

196. Di Guardo, M.; Micheletti, D.; Bianco, L.; Putten, H.J.J.K.-V.; Longhi, S.; Costa, F.; Aranzana, M.J.; Velasco, R.; Arús, P.; Troggio, M.; et al. ASSIsT: An automatic SNP scoring tool for in- and outbreeding species. Bioinformatics 2015, 31, 3873-3874. [CrossRef] [PubMed]

197. Nordborg, M.; Tavaré, S. Linkage disequilibrium: What history has to tell us. Trends Genet. 2002, 18, 83-90. [CrossRef]

198. Machiela, M.J.; Chanock, S.J. LDlink: A web-based application for exploring population-specific haplotype structure and linking correlated alleles of possible functional variants. Bioinformatics 2015, 31, 3555-3557. [CrossRef] [PubMed]

199. Andersen, J.R.; Lübberstedt, T. Functional markers in plants. Trends Plant Sci. 2003, 8, 554-560. [CrossRef] [PubMed]

200. Hodgkinson, K.; Pullman, D. Duty to warn and genetic disease. Canadian journal of cardiovascular nursing. Can. J. Cardiovasc. Nurs. 2010, 20, 12-15. [PubMed]

201. Sun, Y.; Lu, Y.; Xie, L.; Deng, Y.; Li, S.; Qin, X. Interferon gamma polymorphisms and hepatitis B virus-related liver cirrhosis risk in a Chinese population. Cancer Cell Int. 2015, 15, 35. [CrossRef] [PubMed]

202. De Roos, A.; Schrooten, C.; Druet, T. Genomic breeding value estimation using genetic markers, inferred ancestral haplotypes, and the genomic relationship matrix. J. Dairy Sci. 2011, 94, 4708-4714. [CrossRef]

203. Boichard, D.; Guillaume, F.; Baur, A.; Croiseau, P.; Rossignol, M.N.; Boscher, M.Y.; Druet, T.; Genestout, L.; Colleau, J.J.; Journaux, L.; et al. Genomic selection in French dairy cattle. Anim. Prod. Sci. 2012, 52, 115-120. [CrossRef]

204. Edriss, V.; Fernando, R.L.; Su, G.; Lund, M.S.; Guldbrandtsen, B. The effect of using genealogy-based haplotypes for genomic prediction. Genet. Sel. Evol. 2013, 45, 5. [CrossRef]

205. Cuyabano, B.C.; Su, G.; Lund, M.S. Genomic prediction of genetic merit using LD-based haplotypes in the Nordic Holstein population. BMC Genom. 2014, 15, 1171. [CrossRef] [PubMed]

206. Jónás, D.; Ducrocq, V.; Croiseau, P. Short communication: The combined use of linkage disequilibrium-based haploblocks and allele frequency-based haplotype selection methods enhances genomic evaluation accuracy in dairy cattle. J. Dairy Sci. 2017, 100, 2905-2908. [CrossRef]

207. Curtis, D.; North, B.V.; Sham, P.C. Use of an artificial neural network to detect association between a disease and multiple marker genotypes. Ann. Hum. Genet. 2001, 65, 95-107. [CrossRef] [PubMed]

208. Jiang, Y.; Schmidt, R.H.; Reif, J.C. Haplotype-Based Genome-Wide Prediction Models Exploit Local Epistatic Interactions among Markers. G3 Genes Genomes Genet. 2018, 8, 1687-1699. [CrossRef]

209. Liu, F.; Schmidt, R.H.; Reif, J.C.; Jiang, Y. Selecting Closely-Linked SNPs Based on Local Epistatic Effects for Haplotype Construction Improves Power of Association Mapping. G3 Genes Genomes Genet. 2019, 9, 4115-4126. [CrossRef] [PubMed]

210. Du, Q.; Wei, Z.; Zhao, X.; Yang, X.; Ci, N.; Zhang, D. Dissection of additive, dominant, epistatic roles of allelic variation within heat shock factor genes in Chinese indigenous poplar (Populus simonii). Tree Genet. Genomes 2016, 12, 91. [CrossRef]

211. Hickey, J.M.; Dreisigacker, S.; Crossa, J.; Hearne, S.; Babu, R.; Prasanna, B.M.; Grondona, M.; Zambelli, A.D.; Windhausen, V.S.; Mathews, K.; et al. Evaluation of Genomic Selection Training Population Designs and Genotyping Strategies in Plant Breeding Programs Using Simulation. Crop Sci. 2014, 54, 1476-1488. [CrossRef]

212. Calus, M.P.; Meuwissen, T.H.; Windig, J.J.; Knol, E.F.; Schrooten, C.; Vereijken, A.L.; Veerkamp, R.F. Effects of the number of markers per haplotype and clustering of haplotypes on the accuracy of QTL mapping and prediction of genomic breeding values. Genet. Sel. Evol. 2009, 178, 553-561. [CrossRef]

213. Ødegård, J.; Moen, T.; Santi, N.; Korsvoll, S.A.; Kjøglum, S.; Meuwissen, T.H.E. Genomic prediction in an admixed population of Atlantic salmon (Salmo salar). Front. Genet. 2014, 5, 402. [CrossRef]

214. Villumsen, T.; Janss, L.; Lund, M. The importance of haplotype length and heritability using genomic selection in dairy cattle. J. Anim. Breed. Genet. 2009, 126, 3-13. [CrossRef] [PubMed]

215. Rutkoski, J.; Poland, J.; Mondal, S.; Autrique, E.; Pérez, L.G.; Crossa, J.; Reynolds, M.P.; Singh, R. Canopy Temperature and Vegetation Indices from High-Throughput Phenotyping Improve Accuracy of Pedigree and Genomic Selection for Grain Yield in Wheat. G3 Genes Genomes Genet. 2016, 6, 2799-2808. [CrossRef] [PubMed]

216. Lin, Z.; Cogan, N.O.I.; Pembleton, L.W.; Spangenberg, G.C.; Forster, J.W.; Hayes, B.; Daetwyler, H.D. Genetic Gain and Inbreeding from Genomic Selection in a Simulated Commercial Breeding Program for Perennial Ryegrass. Plant Genome 2016, 130, 969-980. [CrossRef] [PubMed] 
217. Eynard, E.S.; Croiseau, P.; Laloë, D.; Fritz, S.; Calus, M.P.L.; Restoux, G. Which Individuals to Choose To Update the Reference Population? Minimizing the Loss of Genetic Diversity in Animal Genomic Selection Programs. G3 Genes Genomes Genet. 2018, 8 , 113-121. [CrossRef]

218. Doublet, A.-C.; Croiseau, P.; Fritz, S.; Michenet, A.; Hozé, C.; Danchin-Burge, C.; Laloë, D.; Restoux, G. The impact of genomic selection on genetic diversity and genetic gain in three French dairy cattle breeds. Genet. Sel. Evol. 2019, 51, 1-13. [CrossRef] [PubMed]

219. Lin, Z.; Shi, F.; Hayes, B.; Daetwyler, H.D. Mitigation of inbreeding while preserving genetic gain in genomic breeding programs for outbred plants. Theor. Appl. Genet. 2017, 130, 969-980. [CrossRef] [PubMed]

220. Sonesson, A.K.; Woolliams, A.J.; Meuwissen, T.H. Genomic selection requires genomic control of inbreeding. Genet. Sel. Evol. 2012, 44, 27. [CrossRef]

221. Daetwyler, H.D.; Hayden, M.; Spangenberg, G.C.; Hayes, B. Selection on Optimal Haploid Value Increases Genetic Gain and Preserves More Genetic Diversity Relative to Genomic Selection. Genetics 2015, 200, 1341-1348. [CrossRef]

222. Leng, P.F.; Lübberstedt, T.; Xu, M.L. Genomics-assisted breeding-A revolutionary strategy for crop improvement. J. Integr. Agric. 2017, 16, 2674-2685. [CrossRef]

223. McKown, A.D.; Klápště, J.; Guy, R.D.; El-Kassaby, Y.A.; Mansfield, S.D. Ecological genomics of variation in bud-break phenology and mechanisms of response to climate warming inPopulus trichocarpa. New Phytol. 2018, 220, 300-316. [CrossRef]

224. Apuli, R.-P.; Richards, T.; Rendón-Anaya, M.; Karacic, A.; Rönnberg-Wästljung, A.-C.; Ingvarsson, P.K. The genetic basis of adaptation in phenology in an introduced population of Black Cottonwood (Populus trichocarpa, Torr. \& Gray). BMC Plant Biol. 2021, 21, 317. [CrossRef]

225. Lamara, M.; Raherison, E.; Lenz, P.; Beaulieu, J.; Bousquet, J.; MacKay, J. Genetic architecture of wood properties based on association analysis and co-expression networks in white spruce. New Phytol. 2015, 210, 240-255. [CrossRef]

226. Hiraoka, Y.; Fukatsu, E.; Mishima, K.; Hirao, T.; Teshima, K.; Tamura, M.; Tsubomura, M.; Iki, T.; Kurita, M.; Takahashi, M.; et al. Potential of Genome-Wide Studies in Unrelated Plus Trees of a Coniferous Species, Cryptomeria japonica (Japanese Cedar). Front. Plant Sci. 2018, 9, 1322. [CrossRef]

227. Gong, C.; Du, Q.; Xie, J.; Quan, M.; Chen, B.; Zhang, D. Dissection of Insertion-Deletion Variants within Differentially Expressed Genes Involved in Wood Formation in Populus. Front. Plant Sci. 2018, 8, 2199. [CrossRef]

228. Chhetri, H.; Furches, A.; Macaya-Sanz, D.; Walker, A.R.; Kainer, D.; Jones, P.; Harman-Ware, A.E.; Tschaplinski, T.J.; Jacobson, D.; Tuskan, G.A.; et al. Genome-Wide Association Study of Wood Anatomical and Morphological Traits in Populus trichocarpa. Front. Plant Sci. 2020, 11, 1391. [CrossRef]

229. Quan, M.; Liu, X.; Du, Q.; Xiao, L.; Lu, W.; Fang, Y.; Li, P.; Ji, L.; Zhang, D. Erratum to: Genome-wide association studies reveal the coordinated regulatory networks underlying photosynthesis and wood formation in Populus. J. Exp. Bot. 2021, 72, 5777-5780. [CrossRef] [PubMed]

230. Müller, B.S.F.; Filho, J.E.D.A.; Lima, B.M.; Garcia, C.C.; Missiaggia, A.; Aguiar, A.M.; Takahashi, E.; Kirst, M.; Gezan, S.A.; Silva-Junior, O.B.; et al. Independent and Joint- GWAS for growth traits in Eucalyptus by assembling genome-wide data for 3373 individuals across four breeding populations. New Phytol. 2018, 221, 818-833. [CrossRef] [PubMed]

231. Bai, Q.; Cai, Y.; He, B.; Liu, W.; Pan, Q.; Zhang, Q. Core set construction and association analysis of Pinus massoniana from Guangdong province in southern China using SLAF-seq. Sci. Rep. 2019, 9, 1-13. [CrossRef] [PubMed]

232. Chen, Y.; Wu, H.; Yang, W.; Zhao, W.; Tong, C. Multivariate linear mixed model enhanced the power of identifying genome-wide association to poplar tree heights in a randomized complete block design. G3 Genes Genomes Genet. 2021, 11, jkaa053. [CrossRef]

233. Liu, J.; Sniezko, R.A.; Zamany, A.; Williams, H.; Wang, N.; Kegley, A.; Savin, D.P.; Chen, H.; Sturrock, R.N. Saturated genic SNP mapping identified functional candidates and selection tools for the Pinus monticola $\mathrm{Cr} 2$ locus controlling resistance to white pine blister rust. Plant Biotechnol. J. 2017, 15, 1149-1162. [CrossRef] [PubMed]

234. Muchero, W.; Sondreli, K.L.; Chen, J.G.; Urbanowicz, B.R.; Zhang, J.; Singan, V.; Yang, Y.; Brueggeman, R.S.; Franco-Coronado, J.; Abraham, N.; et al. Association mapping, transcriptomics, and transient expression identify candidate genes mediating plant-pathogen interactions in a tree. Proc. Natl. Acad. Sci. USA 2018, 115, 11573-11578. [CrossRef]

235. De Lange, W.J.; Veldtman, R.; Allsopp, M.H. Valuation of pollinator forage services provided by Eucalyptus cladocalyx. J. Environ. Manag. 2013, 125, 12-18. [CrossRef] [PubMed]

236. Elfstrand, M.; Baison, J.; Lundén, K.; Zhou, L.; Vos, I.; Capador, H.D.; Åslund, M.S.; Chen, Z.; Chaudhary, R.; Olson, Å.; et al. Association genetics identifies a specifically regulated Norway spruce laccase gene, PaLAC5, linked to Heterobasidion parviporum resistance. Plant Cell Environ. 2020, 43, 1779-1791. [CrossRef] [PubMed]

237. Hall, D.; Hallingbäck, H.R.; Wu, H.X. Estimation of number and size of QTL effects in forest tree traits. Tree Genet. Genomes 2016, 12, 110. [CrossRef]

238. Thumma, B.R.; Southerton, S.G.; Bell, J.C.; Owen, J.V.; Henery, M.L.; Moran, G.F. Quantitative trait locus (QTL) analysis of wood quality traits in Eucalyptus nitens. Tree Genet. Genomes 2010, 6, 305-317. [CrossRef]

239. Du, Q.; Lu, W.; Quan, M.; Xiao, L.; Song, F.; Li, P.; Zhou, D.; Xie, J.; Wang, L.; Zhang, D. Genome-Wide Association Studies to Improve Wood Properties: Challenges and Prospects. Front. Plant Sci. 2018, 9, 1912. [CrossRef] [PubMed]

240. Dort, E.N.; Tanguay, P.; Hamelin, R.C. CRISPR/Cas9 Gene Editing: An Unexplored Frontier for Forest Pathology. Front. Plant Sci. 2020, 11, 1126. [CrossRef] 
241. Elorriaga, E.; Klocko, A.L.; Ma, C.; Strauss, S.H. Variation in Mutation Spectra among CRISPR/Cas9 Mutagenized Poplars. Front. Plant Sci. 2018, 9, 594. [CrossRef]

242. Strauss, S.H.; Costanza, A.; Séguin, A. Genetically engineered trees: Paralysis from good intentions. Science 2015, 349, 794-795. [CrossRef]

243. Strauss, S.H.; Jones, K.N.; Lu, H.; Petit, J.D.; Klocko, A.L.; Betts, M.G.; Brosi, B.J.; Fletcher Jr, R.J.; Needham, M.D. Reproductive modification in forest plantations: Impacts on biodiversity and society. New Phytol. 2017, 213, 1000-1021. [CrossRef]

244. Mussolino, C.; Cathomen, T. RNA guides genome engineering. Nat. Biotechnol. 2013, 31, 208-209. [CrossRef]

245. Koonin, E.V.; Makarova, K.S.; Zhang, F. Diversity, classification and evolution of CRISPR-Cas systems. Curr. Opin. Microbiol. 2017, 37, 67-78. [CrossRef] [PubMed]

246. Demirci, Y.; Zhang, B.; Unver, T. CRISPR/Cas9: An RNA-guided highly precise synthetic tool for plant genome editing. J. Cell. Physiol. 2017, 233, 1844-1859. [CrossRef] [PubMed]

247. Fernandez i Marti, A.F.; Dodd, R.S. Using CRISPR as a gene editing tool for validating adaptive gene function in tree landscape genomics. Front. Ecol. Evol. 2018, 6, 1-7. [CrossRef]

248. Fan, D.; Liu, T.; Li, C.; Jiao, B.; Li, S.; Hou, Y.; Luo, K. Efficient CRISPR/Cas9-mediated Targeted Mutagenesis in Populus in the First Generation. Sci. Rep. 2015, 5, 12217. [CrossRef] [PubMed]

249. Jinek, M.; Chylinski, K.; Fonfara, I.; Hauer, M.; Doudna, J.A.; Charpentier, E. A Programmable Dual-RNA-Guided DNA Endonuclease in Adaptive Bacterial Immunity. Science 2012, 337, 816-821. [CrossRef]

250. Murovec, J.; Pirc, Ž.; Yang, B. New variants of CRISPR RNA-guided genome editing enzymes. Plant Biotechnol. J. 2017, 15, 917-926. [CrossRef]

251. Mao, Y.; Zhang, H.; Xu, N.; Zhang, B.; Gou, F.; Zhu, J.-K. Application of the CRISPR-Cas System for Efficient Genome Engineering in Plants. Mol. Plant 2013, 6, 2008-2011. [CrossRef]

252. Charrier, A.; Vergne, E.; Dousset, N.; Richer, A.; Petiteau, A.; Chevreau, E. Efficient Targeted Mutagenesis in Apple and First Time Edition of Pear Using the CRISPR-Cas9 System. Front. Plant Sci. 2019, 10, 40. [CrossRef]

253. Mao, Y.; Botella, J.R.; Liu, Y.; Zhu, J.-K. Gene editing in plants: Progress and challenges. Natl. Sci. Rev. 2019, 6, 421-437. [CrossRef]

254. Samanta, M.K.; Dey, A.; Gayen, S. CRISPR/Cas9: An advanced tool for editing plant genomes. Transgenic Res. 2016, 25, 561-573. [CrossRef]

255. Ren, C.; Liu, X.; Zhang, Z.; Wang, Y.; Duan, W.; Li, S.; Liang, Z. CRISPR/Cas9-mediated efficient targeted mutagenesis in Chardonnay (Vitis vinifera L.). Sci. Rep. 2016, 6, 32289. [CrossRef]

256. Van Zeijl, A.; Wardhani, T.; Kalhor, M.S.; Rutten, L.; Bu, F.; Hartog, M.; Linders, S.; Fedorova, E.; Bisseling, T.; Kohlen, W.; et al CRISPR/Cas9-Mediated Mutagenesis of Four Putative Symbiosis Genes of the Tropical Tree Parasponia andersonii Reveals Novel Phenotypes. Front. Plant Sci. 2018, 9, 284. [CrossRef]

257. Zhou, X.; Jacobs, T.B.; Xue, L.; Harding, S.A.; Tsai, C. Exploiting SNP s for biallelic CRISPR mutations in the outcrossing woody perennial Populus reveals 4-coumarate: CoA ligase specificity and redundancy. New Phytol. 2015, 208, 298-301. [CrossRef]

258. Bewg, W.P.; Ci, D.; Tsai, C.-J. Genome Editing in Trees: From Multiple Repair Pathways to Long-Term Stability. Front. Plant Sci. 2018, 9, 1732. [CrossRef]

259. Tsai, C.-J.; Xue, L.-J. CRISPRing into the woods. GM Crop. Food 2015, 6, 206-215. [CrossRef]

260. Boerjan, W.; Ralph, J.; Baucher, M. Lignin biosynthesis. Ann. Rev. Plant Boil. 2003, 54, 519-546. [CrossRef]

261. Xu, C.; Fu, X.; Liu, R.; Guo, L.; Ran, L.; Li, C.; Tian, Q.; Jiao, B.; Wang, B.; Luo, K. PtoMYB170 positively regulates lignin deposition during wood formation in poplar and confers drought tolerance in transgenic Arabidopsis. Tree Physiol. 2017, 37, 1713-1726. [CrossRef]

262. Wan, S.; Li, C.; Ma, X.; Luo, K. PtrMYB57 contributes to the negative regulation of anthocyanin and proanthocyanidin biosynthesis in poplar. Plant Cell Rep. 2017, 36, 1263-1276. [CrossRef] [PubMed]

263. Shen, Y.; Li, Y.; Xu, D.; Yang, C.; Li, C.; Luo, K. Molecular cloning and characterization of a brassinosteriod biosynthesis-related gene PtoDWF4 from Populus tomentosa. Tree Physiol. 2018, 38, 1424-1436. [CrossRef] [PubMed]

264. Elorriaga, E.; Klocko, A.L.; Ma, C.; du Plessis, M.; An, X.; Myburg, A.A.; Strauss, S.H. Genetic containment in vegetatively propagated forest trees: CRISPR disruption of LEAFY function in Eucalyptus gives sterile indeterminate inflorescences and normal juvenile development. Plant Biotechnol. J. 2021, 19, 1743-1755. [CrossRef]

265. Sow, M.D.; Allona, I.; Ambroise, C.; Conde, D.; Fichot, R.; Gribkova, S.; Jorge, V.; Le-Provost, G.; Pâques, L.; Plomion, C.; et al. Epigenetics in forest trees: State of the art and potential implications for breeding and management in a context of climate change. Adv. Bot. Res. 2018, 88, 387-453. [CrossRef]

266. Ding, L.; Chen, Y.; Ma, Y.; Wang, H.; Wei, J. Effective reduction in chimeric mutants of poplar trees produced by CRISPR/Cas9 through a second round of shoot regeneration. Plant Biotechnol. Rep. 2020, 14, 549-558. [CrossRef]

267. Bruegmann, T.; Deecke, K.; Fladung, M. Evaluating the Efficiency of gRNAs in CRISPR/Cas9 Mediated Genome Editing in Poplars. Int. J. Mol. Sci. 2019, 20, 3623. [CrossRef] [PubMed]

268. Grattapaglia, D.; Silva-Junior, O.B.; Resende, R.T.; Cappa, E.P.; Müller, B.; Tan, B.; Isik, F.; Ratcliffe, B.; El-Kassaby, Y.A. Quantitative Genetics and Genomics Converge to Accelerate Forest Tree Breeding. Front. Plant Sci. 2018, 9, 1693. [CrossRef]

269. Rennie, E.A.; Hansen, S.F.; Baidoo, E.E.; Hadi, M.Z.; Keasling, J.; Scheller, H.V. Three Members of the Arabidopsis Glycosyltransferase Family 8 Are Xylan Glucuronosyltransferases. Plant Physiol. 2012, 159, 1408-1417. [CrossRef] 
270. Comeau, A.M.; Dufour, J.; Bouvet, G.F.; Jacobi, V.; Nigg, M.; Henrissat, B.; Laroche, J.; Levesque, R.C.; Bernier, L. Functional Annotation of the Ophiostoma novo-ulmi Genome: Insights into the Phytopathogenicity of the Fungal Agent of Dutch Elm Disease. Genome Biol. Evol. 2014, 7, 410-430. [CrossRef]

271. Forgetta, V.; Leveque, G.; Dias, J.; Grove, D.; Lyons Jr, R.; Genik, S.; Wright, C.; Singh, S.; Peterson, N.; Zianni, M. Sequencing of the Dutch elm disease fungus genome using the Roche/454 GS-FLX Titanium System in a comparison of multiple genomics core facilities. J. Biomol. Tech. JBT 2013, 24, 39. [CrossRef] [PubMed]

272. An, Y.; Geng, Y.; Yao, J.; Fu, C.; Lu, M.; Wang, C.; Du, J. Efficient Genome Editing in Populus Using CRISPR/Cas12a. Front. Plant Sci. 2020, 11, 593938. [CrossRef] [PubMed]

273. Jiang, F.; Doudna, J.A. CRISPR-Cas9 Structures and Mechanisms. Annu. Rev. Biophys. 2017, 46, 505-529. [CrossRef] [PubMed]

274. Osakabe, Y.; Sugano, S.S.; Osakabe, K. Genome engineering of woody plants: Past, present and future. J. Wood Sci. 2016, 62, 217-225. [CrossRef]

275. Luo, G.; Palmgren, M. GRF-GIF Chimeras Boost Plant Regeneration. Trends Plant Sci. 2020, 26, 201-204. [CrossRef] [PubMed]

276. Debernardi, J.M.; Tricoli, D.M.; Ercoli, M.F.; Hayta, S.; Ronald, P.; Palatnik, J.F.; Dubcovsky, J. A GRF-GIF chimeric protein improves the regeneration efficiency of transgenic plants. Nat. Biotechnol. 2020, 38, 1274-1279. [CrossRef] [PubMed]

277. Kong, J.; Martin-Ortigosa, S.; Finer, J.; Orchard, N.; Gunadi, A.; Batts, L.A.; Thakare, D.; Rush, B.; Schmitz, O.; Stuiver, M.; et al. Overexpression of the Transcription Factor Growth-Regulating Factor5 Improves Transformation of Dicot and Monocot Species. Front. Plant Sci. 2020, 11, 572319. [CrossRef] [PubMed]

278. Chiurugwi, T.; Kemp, S.; Powell, W.; Hickey, L.T.; Powell, W. Speed breeding orphan crops. Theor. Appl. Genet. 2018, 132, 607-616. [CrossRef]

279. Ghosh, S.; Watson, A.; Gonzalez-Navarro, O.E.; Ramirez-Gonzalez, R.H.; Yanes, L.; Mendoza-Suárez, M.; Simmonds, J.; Wells, R.; Rayner, T.; Green, P.; et al. Speed breeding in growth chambers and glasshouses for crop breeding and model plant research. Nat. Protoc. 2018, 13, 2944-2963. [CrossRef]

280. Watson, A.; Ghosh, S.; Williams, M.J.; Cuddy, W.S.; Simmonds, J.; Rey, M.-D.; Hatta, M.A.M.; Hinchliffe, A.; Steed, A.; Reynolds, D.; et al. Speed breeding is a powerful tool to accelerate crop research and breeding. Nat. Plants 2018, 4, 23-29. [CrossRef] [PubMed]

281. Hickey, L.T.; Hafeez, N.A.; Robinson, H.; Jackson, S.A.; Leal-Bertioli, S.C.M.; Tester, M.; Gao, C.; Godwin, I.D.; Hayes, B.J.; Wulff, B.B.H. Breeding crops to feed 10 billion. Nat. Biotechnol. 2019, 37, 744-754. [CrossRef]

282. Poovaiah, C.; Phillips, L.; Geddes, B.; Reeves, C.; Sorieul, M.; Thorlby, G. Genome Editing With CRISPR/Cas9 in Pinus radiata (D. Don). BMC Plant Boil. 2021, 11, 1734. 